\title{
RESEARCH
}

Open Access

\section{New insights into meningitic Escherichia coli infection of brain microvascular endothelial cells from quantitative proteomics analysis}

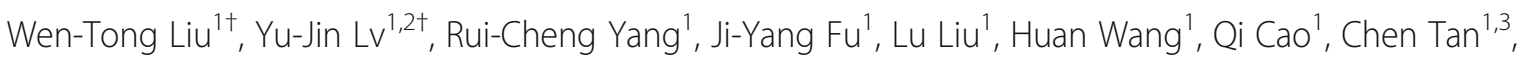
Huan-Chun Chen ${ }^{1,3}$ and Xiang-Ru Wang ${ }^{1,3^{*}}$ (D)

\begin{abstract}
Background: Bacterial meningitis remains a big threat to the integrity of the central nervous system (CNS), despite the advancements in antimicrobial reagents. Escherichia coli is a bacterial pathogen that can disrupt the CNS function, especially in neonates. E. coli meningitis occurs after bacteria invade the brain microvascular endothelial cells (BMECs) that form a direct and essential barrier restricting the entry of circulating microbes and toxins to the brain. Previous studies have reported on several cellular proteins that function during meningitic E. coli infections; however, more comprehensive investigations to elucidate the potential targets involved in E. coli meningitis are essential to better understand this disease and discover new treatments for it.

Methods: The isobaric tags for relative and absolute quantification (iTRAQ) approach coupled with LC-MS/MS were applied to compare and characterize the different proteomic profiles of BMECs in response to meningitic or nonmeningitic E. coli strains. KEGG and gene ontology annotations, ingenuity pathways analysis, and functional experiments were combined to identify the key host molecules involved in the meningitic E. coli-induced tight junction breakdown and neuroinflammatory responses.

Results: A total of 13 cellular proteins were found to be differentially expressed by meningitic E. coli strains PCN033 and RS218, including one that was also affected by HB101, a non-meningitic E. coli strain. Through bioinformatics analysis, we identified the macrophage migration inhibitory factor (MIF), granzyme A, NF-kB signaling, and mitogenactivated protein kinase (MAPK) pathways as being biologically involved in the meningitic E. coli-induced tight junction breakdown and neuroinflammation. Functionally, we showed that MIF facilitated meningitic E. coli-induced production of cytokines and chemokines and also helped to disrupt the blood-brain barrier by decreasing the expression of tight junction proteins like ZO-1, occludin. Moreover, we demonstrated the significant activation of NF-KB and MAPK signaling in BMECs in response to meningitic E. coli strains, which dominantly determined the generation of the proinflammatory cytokines including IL-6, IL-8, TNF-a, and IL-1 $\beta$.

(Continued on next page)
\end{abstract}

\footnotetext{
* Correspondence: wangxr228@mail.hzau.edu.cn

${ }^{\dagger}$ Wen-Tong Liu and Yu-Jin Lv contributed equally to this work.

'The Cooperative Innovation Center for Sustainable Pig Production,

Huazhong Agricultural University, Wuhan 430070, Hubei, China

${ }^{3}$ State Key Laboratory of Agricultural Microbiology, College of Veterinary

Medicine, Huazhong Agricultural University, Wuhan 430070, Hubei, China

Full list of author information is available at the end of the article
}

(c) The Author(s). 2018 Open Access This article is distributed under the terms of the Creative Commons Attribution 4.0 International License (http://creativecommons.org/licenses/by/4.0/), which permits unrestricted use, distribution, and reproduction in any medium, provided you give appropriate credit to the original author(s) and the source, provide a link to the Creative Commons license, and indicate if changes were made. The Creative Commons Public Domain Dedication waiver (http://creativecommons.org/publicdomain/zero/1.0/) applies to the data made available in this article, unless otherwise stated. 


\begin{abstract}
(Continued from previous page)
Conclusions: Our work identified 12 host cellular targets that are affected by meningitic E. coli strains and revealed MIF to be an important contributor to meningitic E. coli-induced cytokine production and tight junction disruption, and also the NF-KB and MAPK signaling pathways that are mainly involved in the infection-induced cytokines production. Characterization of these distinct proteins and pathways in BMECs will facilitate further elucidation of meningitis-causing mechanisms in humans and animals, thereby enabling the development of novel preventative and therapeutic strategies against infection with meningitic E. coli.
\end{abstract}

Keywords: iTRAQ, Proteomics, Blood-brain barrier, BMECs, Meningitic E. coli

\section{Background}

Bacterial meningitis is a severe, life-threatening infection of the central nervous system (CNS) with high morbidity and mortality. It is currently recognized as one of the top ten killers in infection-related deaths worldwide, with almost half of the survivors suffering from diverse neurological sequelae (e.g., mental retardation, hearing impairment and blindness), despite the advancements made in the field of antimicrobial treatment [1-3]. Most bacterial meningitis cases are initiated by hematogenous spread and develop when the circulating bacteria penetrate the blood-brain barrier (BBB), destroy brain parenchyma, and finally cause CNS disorders [1]. Among the meningitis-causing microbes, extraintestinal pathogenic Escherichia coli (ExPEC) has recently emerged as an important zoonotic bacterial pathogen with the potential to colonize multiple tissues outside the intestine and cause severe infections, with one typical outcome being meningitis. The evidence from recent in vivo and in vitro studies indicates that meningitic $E$. coli strains possess the ability to invade the brain, and the infection-induced BBB disruption that occurs is the hallmark event in the development of $E$. coli meningitis $[4,5]$.

The availability of in vitro and in vivo $\mathrm{BBB}$ infection models has made the study of meningitic $E$. coli penetration of the brain possible [6-9]. The in vitro BBB model uses brain microvascular endothelial cells (BMECs) that form distinctive tight junctions and exhibit high trans-endothelial electrical resistance, thereby mimicking the features of the natural in vivo barrier that protects the brain from circulating microorganisms and toxins [10-13]. The in vivo model is established by inducing experimental hematogenous meningitis in newborn rats and mice $[9,14,15]$. With these models, it is now well-established that successful traversal of the BBB by circulating $E$. coli strains requires the following prerequisites: a high bacteremia, binding to and invasion of BMECs, rearrangement of actin cytoskeleton, and crossing the BBB as live bacteria $[1,2]$. These require a series of complicated interactions between meningitic E. coli and the host. So far, several host targets have been found to be associated with this invasion process, including certain intracellular signaling molecules like focal adhesion kinase, phosphatidylinositol 3-kinase (PI3K), Rho
GTPases, cytosolic phospholipase A2, nuclear factor- $k B$ (NF-kB), inducible nitric oxide synthase (NOS), and several cellular surface molecules/receptors such as caveolin-1, Toll-like receptors, the intercellular adhesion molecule (ICAM-1), and some actin-binding molecules like ERM family proteins (ezrin, radixin, and moesin), most likely through their influences on the aforementioned prerequisites [8, 16-19]. We have previously identified and characterized two essential cellular targets, S1P and EGFR, which are exploited by meningitic $E$. coli for successful invasion of the BBB [20]. In other work, we have also found that vascular endothelial growth factor A (VEGFA) and Snail-1, which are inducible by meningitic $E$. coli, can mediate the BBB disruption [5]. Despite these advances, the mechanisms involved in CNS infection by meningitic $E$. coli are still poorly understood, and a more comprehensive investigation to elucidate the cellular targets in infected BMECs is now required.

In the current study, we compared the different proteomic profiles of BMECs in response to meningitic and non-meningitic $E$. coli strains via the isobaric tags for relative and absolute quantification (iTRAQ) approach and investigated the potential host factors and mechanisms that were hijacked by meningitic $E$. coli to penetrate the BBB. Characterization of these potential host targets will expand our current knowledge on meningitic E. coli-induced CNS infections and provide new strategies to prevent this infection and develop novel therapeutic reagents against it.

\section{Methods}

\section{Bacterial strains, cell culture, and infection}

The E. coli K1 strain RS218 (O18:K1:H7) [GenBank: CP007149.1], whose genomic sequencing has been finalized and annotated, is a well-characterized cerebrospinal fluid (CSF) isolate from a neonatal meningitis case [21]. The porcine-originated ExPEC strain PCN033 (O11: K2) [GenBank: CP006632.1], which was isolated from swine CSF in China [22, 23], is evidenced to be highly virulent and capable of invading and disrupting the BBB, thereby causing CNS dysfunction [5, 24]. E. coli K12 strain HB101 is an avirulent and non-meningitic strain normally used as a negative control strain [25, 26]. All $E$. 
coli strains were grown aerobically at $37{ }^{\circ} \mathrm{C}$ in LuriaBertani medium unless otherwise specified.

The immortalized human BMECs (hereafter called hBMECs) were kindly provided by Prof. Kwang Sik Kim in Johns Hopkins University School of Medicine and routinely cultured in RPMI 1640 supplemented with 10\% fetal bovine serum, $2 \mathrm{mM}$ L-glutamine, $1 \mathrm{mM}$ sodium pyruvate, essential amino acids, nonessential amino acids, vitamins, and penicillin and streptomycin $(100 \mathrm{U} / \mathrm{mL})$ in a $37{ }^{\circ} \mathrm{C}$ incubator under $5 \% \mathrm{CO}_{2}$ until monolayer confluence was reached [20, 27]. Confluent cells were washed with Hank's balanced salt solution (Corning Cellgro, Manassas, VA, USA) and starved in serum-free medium for 16-18 h before further treatment. For bacterial challenge, the cells were infected with E. coli PCN033, RS218, or HB101 strains each at a multiplicity of infection of 10 for $2 \mathrm{~h}$. In some assays, the cells were pretreated with specific inhibitors prior to bacterial challenge.

\section{Reagents, antibodies, and inhibitors}

The p38 inhibitor SB202190, extracellular signal-regulated kinases 1 and 2 (ERK1/2) inhibitor U0126, c-Jun $\mathrm{N}$-terminal kinase (JNK) inhibitor SP600125, NF- $\mathrm{kB}$ inhibitor BAY11-7082, and (S, R)-3-(4-hydroxyphenyl)-4, 5-dihydro-5-isoxazole acetic acid methyl ester (ISO-1), an inhibitor of macrophage migration inhibitory factor (MIF), were purchased from MedChem Express (Monmouth, NJ, USA). Recombinant MIF protein was purchased from Novoprotein (Summit, NJ, USA). The nucleic acid dye, 4'-6-diamidino-2-phenylindole (DAPI), was obtained from Solarbio (Beijing, China). Anti-ZO-1, anti-MIF, anti-TATA box-binding protein-like protein 1 (TBPL1), anti-legumain (LGMN), anti-ERK1/2, and anti-phospho-ERK1/2 antibodies (all rabbit) were purchased from ABclonal (Wuhan, Hubei, China). Anti-occludin, anti-dystrophin (DMD), anti-HISTIHIC, anti-JNK, and anti-p38 mitogen-activated protein kinase (MAPK) antibodies (all rabbit) were purchased from Proteintech (Chicago, IL, USA). Anti-phospho-JNK (rabbit) antibody was from R\&D Systems (Minneapolis, MO, USA). Anti-phospho-p38, anti-p65, anti-phospho-p65, and anti-IкB $\alpha$ antibodies (all rabbit) were purchased from Cell Signaling Technology (Danvers, MA, USA). Cy3-labeled goat anti-rabbit antibody was purchased from Beyotime Institute of Biotechnology (Shanghai, China). Anti-GAPDH (mouse) antibody was purchased from Beijing Biodragon Immunotechnologies Co., Ltd. (Beijing, China).

\section{Protein isolation, digestion, and labeling with iTRAQ reagents}

Bacterial-infected and non-infected cells in $10 \mathrm{~cm}$ dishes were collected 2-h post-infection and gently washed with pre-chilled PBS buffer. The cells were lysed in $1 \mathrm{~mL}$ lysis buffer, and the soluble protein fraction was harvested by
5 min of ultrasonication treatment (pulse on $2 \mathrm{~s}$, pulse off $3 \mathrm{~s}$, power $180 \mathrm{~W}$ ) followed by centrifugation at $20000 \times g$ for $30 \mathrm{~min}$ at $4{ }^{\circ} \mathrm{C}$, and the protein concentration was determined via the Bradford protein assay method with BSA as the standard substance. The proteins were reduced with $10 \mathrm{mM}$ iodoacetamide at room temperature for $45 \mathrm{~min}$ in the dark and then precipitated in acetone at $-20{ }^{\circ} \mathrm{C}$ for $3 \mathrm{~h}$. After centrifugation at $20000 \times g$ for $20 \mathrm{~min}$, the protein pellet was resuspended and ultrasonicated in pre-chilled 50\% (w/v) tetraethyl-ammonium bromide (TEAB) buffer supplemented with $0.1 \%$ SDS. The proteins were obtained after centrifugation at $20000 \times g$ and their concentrations were measured by Bradford assays.

Subsequently, protein $(100 \mu \mathrm{g})$ in TEAB buffer was incubated with $3.3 \mu \mathrm{L}$ of trypsin $(1 \mu \mathrm{g} / \mu \mathrm{L})$ (Promega, Madison, WI, USA) at $37{ }^{\circ} \mathrm{C}$ for $24 \mathrm{~h}$ in a sealed tube. The tryptic peptides were lyophilized and dissolved in 50\% TEAB buffer, and iTRAQ labeling was performed according to the manufacturer's instructions (AB Sciex, Foster City, CA, USA). Briefly, one unit of iTRAQ reagent was thawed and reconstituted in $24 \mu \mathrm{L}$ isopropanol and the peptides were incubated at room temperature for $2 \mathrm{~h}$. The peptides from the control, HB101, PCN033, and RS218 groups were designated $114,115,116$, and 117 , respectively. The labeled samples were then mixed and dried with a rotary vacuum concentrator. The labeling efficiency was examined by mass spectrometry (MS).

\section{Strong cation exchange chromatography (SCX) fractionation and liquid chromatography (LC)-MS/MS analysis}

The labeled samples were pooled and purified using an SCX column (Phenomenex, USA), and separated by LC using an LC-20AB HPLC pump system (Shimadzu, Japan). The peptides were then mixed with nine times their volume in buffer A $\left(25 \% \mathrm{ACN}, 10 \mathrm{mM} \mathrm{KH} \mathrm{PO}_{4}\right.$, $\mathrm{pH}=3)$ and loaded onto a $4.6 \times 250 \mathrm{~mm}$ Ultremex SCX column containing $5-\mu \mathrm{m}$ particles (Phenomenex). The peptides were eluted at a flow rate of $1 \mathrm{ml} / \mathrm{min}$ in a buffer B (25\% ACN, $\left.2 \mathrm{M} \mathrm{KCL}, 10 \mathrm{mM} \mathrm{KH}_{2} \mathrm{PO}_{4}, \mathrm{pH}=3\right)$ gradient as follows: $0-5 \%$ buffer $\mathrm{B}$ for $30 \mathrm{~min}, 5-30 \%$ buffer B for $20 \mathrm{~min}, 30-50 \%$ buffer B for $5 \mathrm{~min}, 50 \%$ buffer B for $5 \mathrm{~min}, 50-100 \%$ buffer B for $5 \mathrm{~min}$, and $100 \%$ buffer B for 1 min before equilibrating with buffer A for 10 min prior to the next injection. Next, the eluted peptides were desalted with a Strata X C18 column (100 mm $\times 75 \mathrm{~mm}, 5$-um particles, 300A aperture) (Phenomenex, Torrance, CA, USA) and vacuum dried. The fractions were then dissolved in aqueous solution containing $0.1 \%$ formic acid (FA) and $2 \% \mathrm{ACN}$ and centrifuged at $12000 \mathrm{~g}$ for $10 \mathrm{~min}$ at $4{ }^{\circ} \mathrm{C}$. Five micrograms supernatant was loaded on an LC-20AD nano HPLC (Shimadzu, Kyoto, Japan) by the autosampler onto a $2 \mathrm{~cm} \mathrm{C18} \mathrm{trap} \mathrm{column} \mathrm{(inner} \mathrm{diameter} 200 \mu \mathrm{m}$, Waters), 
and the peptides were eluted onto a resolving $10 \mathrm{~cm}$ analytical C18 column (inner diameter $75 \mu \mathrm{m}$, Waters). The mobile phases used were composed of solvent A (0.1\% FA and 5\% ACN) and solvent B (0.1\% FA and 95\% $\mathrm{ACN})$. The gradient was run at $400 \mathrm{~nL} / \mathrm{min}$ for $48 \mathrm{~min}$ at $5-80 \%$ solvent $\mathrm{B}$, followed by running a linear gradient to $80 \%$ for $7 \mathrm{~min}$, maintained at $80 \%$ B for $3 \mathrm{~min}$, and finally returned to $5 \%$ in $7 \mathrm{~min}$.

The peptides were subjected to nano-electrospray ionization followed by tandem mass spectrometry (MS/ MS) in a Q EXACTIVE (Thermo Fisher Scientific, San Jose, CA, USA) coupled to the HPLC. Intact peptides were detected in the Orbitrap at a resolution of 70,000 and a mass range of $350-2000 \mathrm{~m} / \mathrm{z}$. Peptides were selected for MS/MS using high-energy collision dissociation (HCD), and ion fragments were detected in the Orbitrap at a resolution of 17,500. The electrospray voltage applied was $1.8 \mathrm{kV}$. MS/MS analysis was required for the 15 most abundant precursor ions, which were above a threshold ion count of 20,000 in the MS survey scan, including a following dynamic exclusion duration of $15 \mathrm{~s}$.

\section{ITRAQ data analysis}

The raw data files acquired from the mass spectrometers were converted into MGF files using 5600 MS Converter. Protein identification and quantification were performed using the Mascot Server (http://www.matrixscience.com/ search_form_select.html) against the Uniprot_2015_human database (Matrix Science, London, UK; version 2.3.0) and Proteome Discoverer 1.3 (Thermo Fisher Scientific Inc.). To reduce the probability of false peptide identification, only peptides with significance scores at the $95 \%$ confidence interval as determined by a Mascot probability analysis were included. The quantitative protein ratios were weighted and normalized by the median ratio in Mascot. Statistical significance analyses were evaluated using two-way ANOVA. The proteins were considered to be differentially expressed if the ratio of mean fold change $>1.2$ (or $<0.83$ ) with an Exp pr $>0.05$ and a Group pr $<$ 0.05 (Exp pr, three-experiment $p$ value; Group pr, group $p$ value; fold change $=$ experiment + group + error) .

The Gene Ontology (GO) annotation of the identified proteins was performed via the online GO program (http://geneontology.org/). The biological functions, networks, and signaling pathways of the differentially expressed proteins (DEPs) were analyzed with Ingenuity Pathways Analysis (IPA) software (version 7.5, http:// www.ingenuity.com) (Additional files 8, 9 and 10).

\section{RNA extraction and quantitative real-time PCR}

Total RNA from the uninfected or infected cells was extracted with RNAiso Plus reagent according to the manufacturer's instructions (TakaRa, Japan). Any genomic DNA contamination was eliminated by DNase I treatment, and the RNA was reverse-transcribed into cDNA using the PrimeScript $^{\text {tix }}$ RT reagent kit with gDNA Eraser, following the manufacturer's instructions (Takara, Japan). Quantitative real-time PCR was performed in triplicate using the Power SYBR Green PCR Master Mix (Applied BioSystems, Foster City, CA, USA). The PCR primers for these experiments are listed in Table 1. The expression levels of the target genes were normalized to GAPDH by the $2^{-\Delta \Delta C T}$ method.

\section{Western blotting}

Uninfected and infected hBMECs were collected and lysed in RIPA buffer supplemented with a protease inhibitor cocktail (Sigma-Aldrich, St. Louis, MO, USA) and then sonicated and centrifuged at $10,000 \times g$ for $10 \mathrm{~min}$ at $4{ }^{\circ} \mathrm{C}$. The soluble protein concentration in the supernatants was measured using the BCA protein assay kit (Beyotime, China). Aliquots from each sample were separated by $12 \%$ SDS-PAGE, and then transferred to polyvinylidene difluoride membranes (Bio-Rad, CA, USA). The blots were blocked with 5\% BSA in Tris-buffered saline with Tween 20 at room temperature for $1 \mathrm{~h}$ and then incubated overnight at $4{ }^{\circ} \mathrm{C}$ with primary antibodies against GAPDH, DMD, MIF, HIST1H1C, TBPL1 or LGMN. The blots were subsequently washed and incubated with horseradish peroxidase-conjugated anti-rabbit or anti-mouse IgG at $37{ }^{\circ} \mathrm{C}$ for $1 \mathrm{~h}$, and visualized with ECL reagents (Bio-Rad, USA). The blots were densitometrically quantified and analyzed with Image Lab software (Bio-Rad).

\section{Immunofluorescence microscopy}

Uninfected and infected hBMECs were fixed with $4 \%$ paraformaldehyde and permeabilized with $0.2 \%$ Triton X-100. After $2 \mathrm{~h}$ of blocking in PBS buffer with 5\% BSA, the cells were incubated with the primary antibody (1:100) overnight at $4{ }^{\circ} \mathrm{C}$, washed thrice with PBS, and then incubated with fluorescently labeled anti-mouse or anti-rabbit IgG (1500) for $1 \mathrm{~h}$. Nuclei were stained with DAPI

Table 1 Primers used for real-time PCR in this study

\begin{tabular}{lll}
\hline Primers & Nucleotide sequence(5'-3') & Gene symbol(s) \\
\hline P1 & ACGAATCTCCGACCACT & IL-1 $\beta$ \\
P2 & CCATGGCCACAACAACTGAC & \\
P3 & CTCAGCCTCTTCTCCTTC & TNF-a \\
P4 & GGGTTTGCTACAACATGG & \\
P5 & CCACTCACCTCTTCAGAA & $\mathbb{L L}-6$ \\
P6 & GGCAAGTCTCCTCATTGA & \\
P7 & GACATACTCCAAACCTTTCC & $\mathbb{I L - 8}$ \\
P8 & ATTCTCAGCCCTCTTCAAA & \\
P9 & TGCCTCCTGCACCACCAACT & GAPDH \\
P10 & CGCCTGCTTCACCACCTTC & \\
\hline
\end{tabular}


$(0.5 \mu \mathrm{g} / \mathrm{mL})$ for $30 \mathrm{~min}$. Finally, the cells were mounted and then visualized with fluorescence microscopy.

\section{Electric cell substrate impedance sensing (ECIS)}

To explore the influence of recombinant MIF on the permeability of the BBB, hBMECs were seeded at $7 \times 10^{4}$ cells on collagen-coated, gold-plated electrodes in 96-well chamber slides $(96 \mathrm{~W} 1 \mathrm{E}+$ ) linked to ECIS Z $\theta$ equipment (Applied BioPhysics, Troy, NY, USA) and continuously cultured until confluence, and the trans-endothelial electric resistance (TEER) was monitored to reflect the formation of the barrier [28]. After stable maximal TEER was reached, the recombinant human MIF protein was added into the cells at multiple dosages $(10,100$, and $200 \mathrm{ng} /$ $\mathrm{mL}$ ), and the possible TEER alteration of the monolayer cells was automatically recorded by the ECIS system.

\section{Statistical analysis}

Data were expressed as the mean \pm standard deviation $($ mean \pm SD) from three replicates. Statistical significance of the differences between each group was analyzed by a one-way analysis of variance (ANOVA) or two-way ANOVA embedded in GraphPad Prism, version 6.0 (GraphPad Software Inc., La Jolla, CA, USA). $P<0.05\left(^{*}\right)$ was considered statistically significant, and $p<0.01^{(* *)}$ ), as well as $\left.p<0.001{ }^{* * * *}\right)$ were all considered extremely significant.

\section{Results}

Differential protein profiling of hBMECs in response to $E$. coli infection

The protein extracts prepared from the hBMECs with or without meningitic $E$. coli challenge were subjected to the iTRAQ proteomics analysis. The whole work flow was shown in Fig. 1. Approximately 3000 different proteins were identified and quantified by iTRAQ-coupled LC-MS/MS analysis of the hBMECs infected with E. coli HB101, PCN033, or RS218 strains (Additional file 1: Table S1, Additional file 2: Table S2, Additional file 3: Table S3). As shown in Fig. 2a-d, four proteins were identified as being significantly upregulated and two were significantly downregulated upon HB101 infection, six were significantly upregulated, and 72 were significantly downregulated upon PCN033 infection, while 16 significantly upregulated and 27 significantly downregulated proteins were identified in cells challenged with RS218. The details of these differentially expressed proteins (DEPs) are listed in Tables 2, 3, and 4. The meningitic E. coli PCN033 group displayed 65 unique proteins, while the RS218 group displayed 27 unique proteins. They both shared 13 DEPs with 12 of them being distinct proteins in the hBMECs in response to meningitic strains PCN033 and RS218 (Fig. 2e, Table 5). Only one protein, EXOSC4, was shared by the three groups, and it showed a 0.74-, 0.759-, and 0.8-fold decrease in HB101, PCN033 and RS218 groups, respectively (Fig. 2e, Table 5). In contrast, infection with the non-meningitic HB101 strain induced only two unique, differentially altered proteins. Four proteins were shared between HB101 and RS218 groups, and the three of them altered in response to HB101 and RS218 were specific host proteins in both of these human isolates (Fig. 2e).

\section{Western blot verification of the DEPs}

We next used western blotting to further test the DEPs identified by iTRAQ. We selected several proteins from the iTRAQ results from both PCN033 and

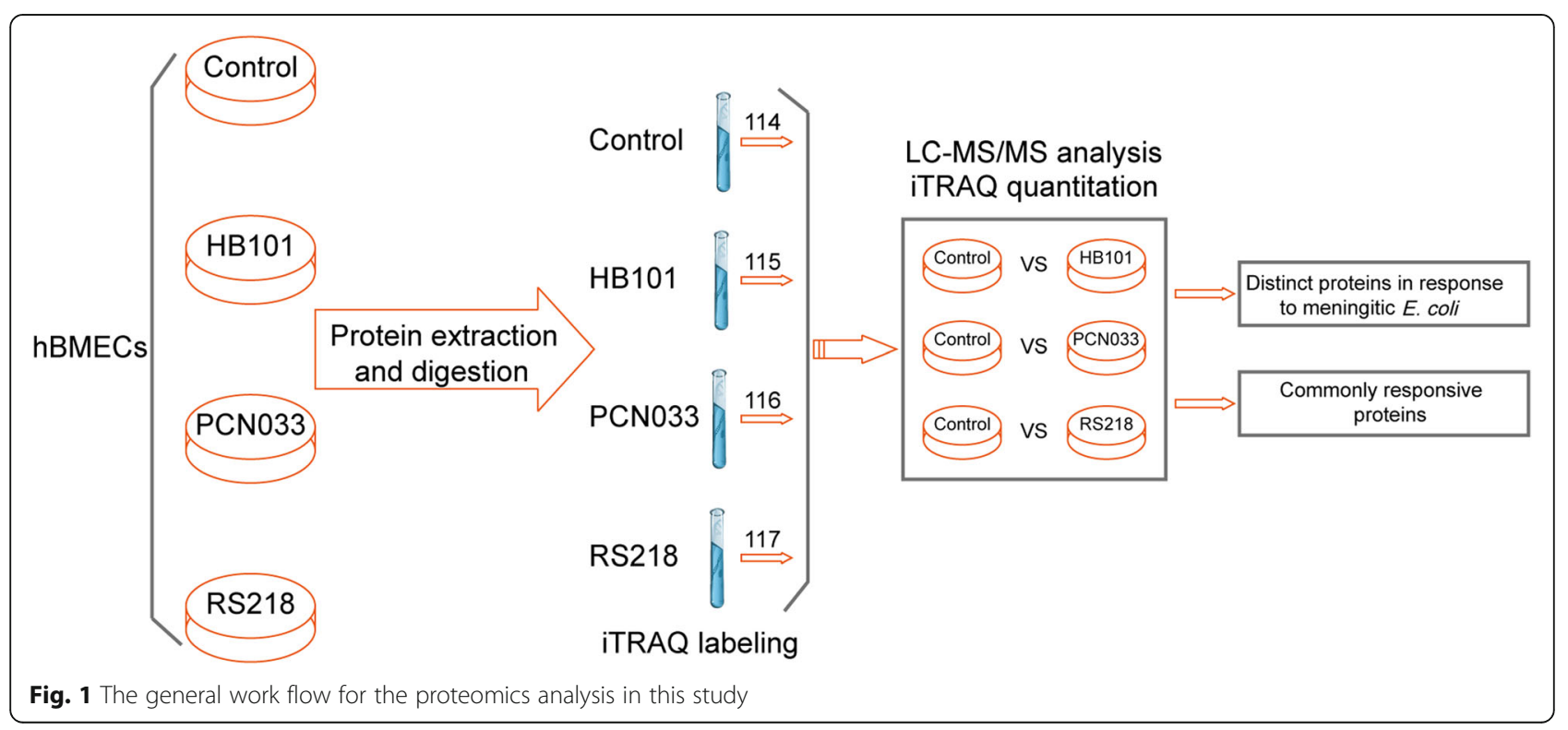




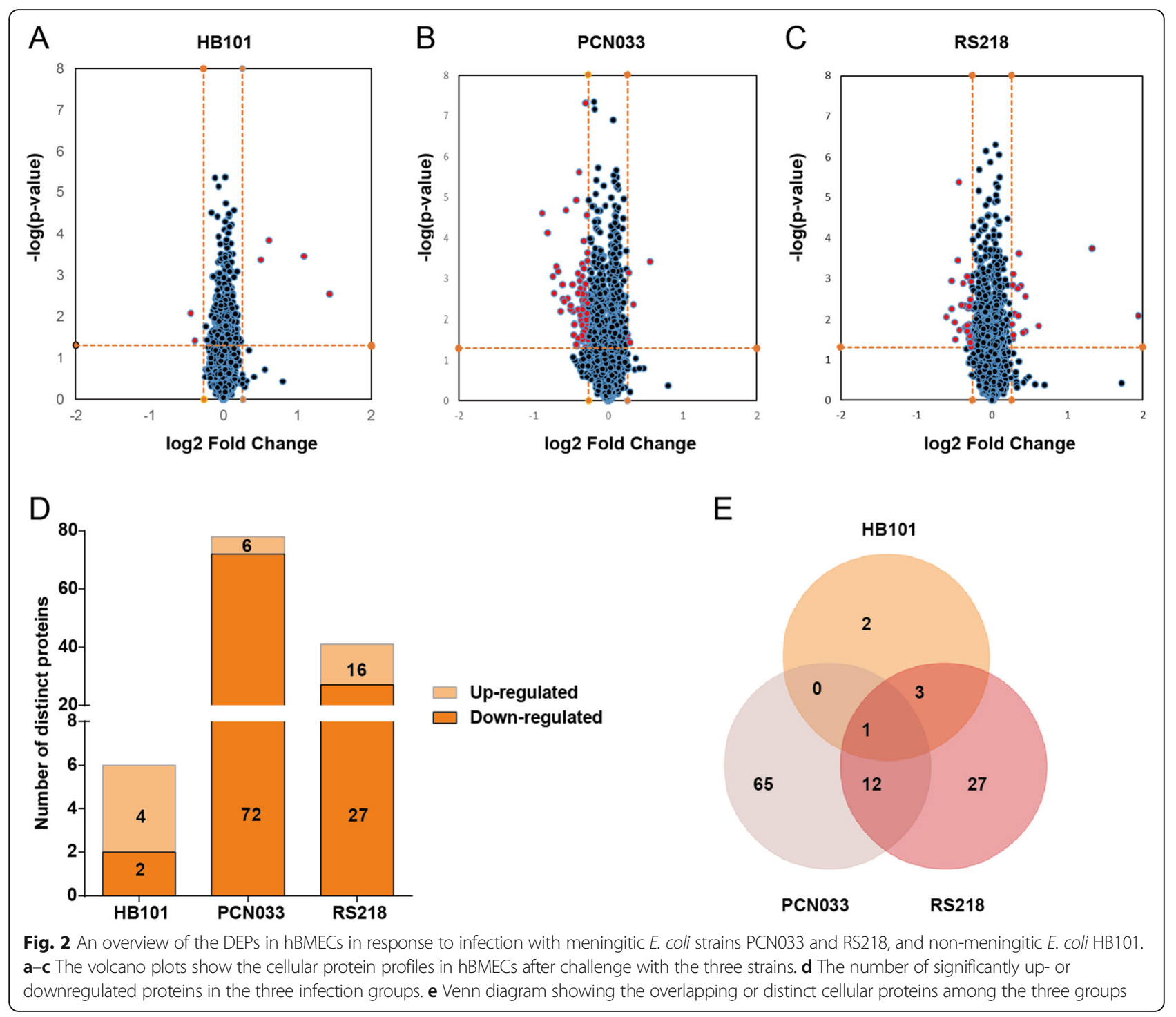

RS218 groups. The test proteins were HIST1H1C, TBPL1, and MIF for the PCN033 group (Fig. 3a), and DMD, LGMN, and HIST1H1C for the RS218 group (Fig. 3c). The western blot and densitometry analyses produced the similar expression alteration to those of the iTRAQ results following either PCN033 or RS218 infection (Fig. 3b, d).
Bioinformatic analysis of the DEPs in hBMECs

We next investigated and characterized the DEPs by searching the GO and UniProt databases. The DEPs were assigned to the categories of different "biological processes," "cellular components," and "molecular functions." Within the biological processes class, the DEPs from the three groups (RS218, PCN033, and HB101)

Table 2 Significantly changed proteins in HB101-infected hBMECs

\begin{tabular}{lllll}
\hline Accession & Description & MW [kDa] & Fold change & $P$ value \\
\hline P02656 & Apolipoprotein C-III & 10.8 & 1.544 & $0.000144^{* * *}$ \\
Q07020 & 60S ribosomal protein L18 & 21.6 & 1.422 & $0.000429^{* * *}$ \\
Q96HP4 & Oxidoreductase NAD-binding domain-containing protein 1 & 34.8 & 2.715 & $0.002873^{* *}$ \\
Q9NPD3 & Exosome complex component RRP41 & 26.4 & 0.737 & $0.008415^{* *}$ \\
Q9Y2Q5 & Ragulator complex protein LAMTOR2 & 13.5 & 0.769 & $0.038574^{*}$ \\
O14556 & Glyceraldehyde-3-phosphate dehydrogenase, testis-specific & 44.5 & 2.134 & $0.000347^{* * *}$ \\
\hline
\end{tabular}

${ }^{\mathrm{a}} P<0.05\left(^{*}\right)$ was considered significant, and $P<0.01{ }^{(*)}$, as well as $\left.<0.001{ }^{(* *}\right)$ were all considered extremely significant 
Table 3 Significantly changed proteins in PCN033-infected hBMECs

\begin{tabular}{|c|c|c|c|c|}
\hline Accession & Description & MW [kDa] & Fold change & $P$ value ${ }^{a}$ \\
\hline A6ZKI3 & Protein FAM127A & 13.2 & 0.756 & $0.028947^{*}$ \\
\hline 000625 & Pirin & 32.1 & 1.228 & $0.037445^{*}$ \\
\hline O43633 & Charged multivesicular body protein 2a & 25.1 & 0.758 & $0.002376^{* *}$ \\
\hline O43752 & Syntaxin-6 & 29.2 & 0.79 & $0.025619^{*}$ \\
\hline O60524 & Nuclear export mediator factor NEMF & 122.9 & 0.83 & $0.004194^{* *}$ \\
\hline O75190 & DnaJ homolog subfamily B member 6 & 36.1 & 0.799 & $0.020038^{*}$ \\
\hline O75251 & NADH dehydrogenase [ubiquinone] iron-sulfur protein 7, mitochondrial & 23.5 & 0.711 & $0.004822^{* *}$ \\
\hline O75817 & Ribonuclease $\mathrm{P}$ protein subunit p20 & 15.6 & 0.815 & $0.017814^{*}$ \\
\hline O95229 & ZW10 interactor & 31.3 & 0.668 & $0.003727^{* *}$ \\
\hline P04004 & Vitronectin & 54.3 & 0.808 & $0.003548^{* *}$ \\
\hline P07305 & Histone $\mathrm{H} 1.0$ & 20.9 & 0.776 & $0.008176^{* *}$ \\
\hline P11532 & Dystrophin & 426.5 & 0.691 & $0.003088^{* *}$ \\
\hline P14174 & Macrophage migration inhibitory factor & 12.5 & 1.486 & $0.000377^{* * *}$ \\
\hline P16401 & Histone H1.5 & 22.6 & 0.631 & $0.000673^{* * *}$ \\
\hline P16402 & Histone H1.3 & 22.3 & 0.6 & $0.000896^{* * *}$ \\
\hline P16403 & Histone H1.2 & 21.4 & 0.572 & 7.57E-05*** \\
\hline P35251 & Replication factor $C$ subunit 1 & 128.2 & 0.786 & $0.013936^{*}$ \\
\hline P35527 & Keratin, type I cytoskeletal 9 & 62 & 0.72 & $0.001431^{* *}$ \\
\hline P39060 & Collagen alpha-1(XVIII) chain & 178.1 & 0.792 & $0.031694^{*}$ \\
\hline P46013 & Antigen $\mathrm{Kl}-67$ & 358.5 & 0.793 & $0.005934^{* *}$ \\
\hline P48651 & Phosphatidylserine synthase 1 & 55.5 & 0.83 & $0.000234^{* * *}$ \\
\hline P49585 & Choline-phosphate cytidylyltransferase A & 41.7 & 0.608 & $0.002306^{* *}$ \\
\hline P50914 & 605 ribosomal protein L14 & 23.4 & 0.71 & $0.005946^{* *}$ \\
\hline P52756 & RNA-binding protein 5 & 92.1 & 0.758 & $0.005815^{* *}$ \\
\hline P56377 & AP-1 complex subunit sigma-2 & 18.6 & 0.765 & $2.4 \mathrm{E}-06^{* * *}$ \\
\hline P61966 & AP-1 complex subunit sigma-1A & 18.7 & 0.814 & $4.81 \mathrm{E}-08^{* * *}$ \\
\hline P62277 & $40 \mathrm{~S}$ ribosomal protein S13 & 17.2 & 0.792 & $0.002441^{* *}$ \\
\hline P62380 & TATA box-binding protein-like protein 1 & 20.9 & 0.621 & $0.000503^{* * *}$ \\
\hline Q13625 & Apoptosis-stimulating of p53 protein 2 & 125.5 & 0.724 & $0.006481^{* *}$ \\
\hline Q14241 & Transcription elongation factor B polypeptide 3 & 89.9 & 0.647 & $0.006556^{* *}$ \\
\hline Q14686 & Nuclear receptor coactivator 6 & 219 & 0.792 & $0.005234^{* *}$ \\
\hline Q15388 & Mitochondrial import receptor subunit TOM20 homolog & 16.3 & 0.823 & $0.007395^{* *}$ \\
\hline Q15629 & Translocating chain-associated membrane protein 1 & 43 & 0.809 & $0.023084^{*}$ \\
\hline Q17RN3 & Protein FAM98C & 37.3 & 0.821 & $0.010317^{*}$ \\
\hline Q4V339 & COBW domain-containing protein 6 & 43.9 & 0.747 & $1.2 \mathrm{E}-05^{* * *}$ \\
\hline Q567U6 & Coiled-coil domain-containing protein 93 & 73.2 & 0.814 & $0.001351^{* *}$ \\
\hline Q5SSJ5 & Heterochromatin protein 1-binding protein 3 & 61.2 & 0.828 & $0.000364^{* * *}$ \\
\hline Q6N069 & $\mathrm{N}$-alpha-acetyltransferase 16, NatA auxiliary subunit & 101.4 & 0.775 & $0.001734^{* *}$ \\
\hline Q709C8 & Vacuolar protein sorting-associated protein $13 \mathrm{C}$ & 422.1 & 0.799 & $0.000576^{* * *}$ \\
\hline Q7Z422 & SUZ domain-containing protein 1 & 17 & 0.808 & $0.002542^{* *}$ \\
\hline Q8IXJ9 & Putative Polycomb group protein ASXL1 & 165.3 & 0.807 & $0.007037^{* *}$ \\
\hline Q8N2K0 & Monoacylglycerol lipase ABHD12 & 45.1 & 0.786 & $0.0034^{* *}$ \\
\hline Q8N884 & Cyclic GMP-AMP synthase & 58.8 & 0.82 & $0.013058^{*}$ \\
\hline Q8NC44 & Protein FAM134A & 57.8 & 0.78 & $0.010814^{*}$ \\
\hline
\end{tabular}


Table 3 Significantly changed proteins in PCN033-infected hBMECs (Continued)

\begin{tabular}{|c|c|c|c|c|}
\hline Accession & Description & $\mathrm{MW}[\mathrm{kDa}]$ & Fold change & $P$ value $^{a}$ \\
\hline Q8NC60 & Nitric oxide-associated protein 1 & 78.4 & 0.81 & $0.013637^{*}$ \\
\hline Q8NEY1 & Neuron navigator 1 & 202.3 & 0.797 & $0.020924^{*}$ \\
\hline Q8TEM1 & Nuclear pore membrane glycoprotein 210 & 205 & 0.833 & $0.032212^{*}$ \\
\hline Q8WUP2 & Filamin-binding LIM protein 1 & 40.6 & 0.809 & $0.002633^{* *}$ \\
\hline Q8WW9 & Heterogeneous nuclear ribonucleoprotein L-like & 60 & 0.804 & $0.013638^{*}$ \\
\hline Q8WXA3 & RUN and FYVE domain-containing protein 2 & 75 & 0.744 & $0.041934^{*}$ \\
\hline Q92604 & Acyl-CoA:lysophosphatidylglycerol acyltransferase 1 & 43.1 & 0.789 & $0.033787 *$ \\
\hline Q96A57 & Transmembrane protein 230 & 13.2 & 0.786 & $0.000449^{* * *}$ \\
\hline Q96LB3 & Intraflagellar transport protein 74 homolog & 69.2 & 0.543 & $2.53 \mathrm{E}-05^{* * *}$ \\
\hline Q96RU3 & Formin-binding protein 1 & 71.3 & 0.679 & $2.07 \mathrm{E}-05^{* * *}$ \\
\hline Q96T37 & Putative RNA-binding protein 15 & 107.1 & 0.728 & $0.024086^{*}$ \\
\hline Q9GZP8 & Immortalization upregulated protein & 10.9 & 1.207 & $0.032624^{*}$ \\
\hline Q9H074 & Polyadenylate-binding protein-interacting protein 1 & 53.5 & 1.266 & $0.004395^{* *}$ \\
\hline Q9H5N1 & Rab GTPase-binding effector protein 2 & 63.5 & 0.77 & $0.001156^{* *}$ \\
\hline Q9H5X1 & MIP18 family protein FAM96A & 18.3 & 0.8 & $0.000118^{* * *}$ \\
\hline Q9HB40 & Retinoid-inducible serine carboxypeptidase & 50.8 & 1.215 & $0.000733^{* * *}$ \\
\hline Q9HC52 & Chromobox protein homolog 8 & 43.4 & 1.201 & $0.023152^{*}$ \\
\hline Q9NPD3 & Exosome complex component RRP41 & 26.4 & 0.759 & $0.000746^{* * *}$ \\
\hline Q9NRY4 & Rho GTPase-activating protein 35 & 170.4 & 0.792 & $0.011172^{*}$ \\
\hline Q9NS87 & Kinesin-like protein KIF15 & 160.1 & 0.785 & $0.010039^{*}$ \\
\hline Q9NSP4 & Centromere protein $\mathrm{M}$ & 19.7 & 0.802 & $0.021316^{*}$ \\
\hline Q9NTI5 & Sister chromatid cohesion protein PDS5 homolog B & 164.6 & 0.826 & $0.003399^{* *}$ \\
\hline Q9NWU5 & 395 ribosomal protein L22, mitochondrial & 23.6 & 0.812 & $0.016677^{*}$ \\
\hline Q9NZQ3 & NCK-interacting protein with $\mathrm{SH} 3$ domain & 78.9 & 0.661 & $0.00317^{* *}$ \\
\hline Q9P0V3 & SH3 domain-binding protein 4 & 107.4 & 0.797 & $0.001833^{* *}$ \\
\hline Q9UBL6 & Copine-7 & 70.2 & 0.823 & $2.73 \mathrm{E}-05^{* * *}$ \\
\hline Q9UJW0 & Dynactin subunit 4 & 52.3 & 0.823 & $0.012604^{*}$ \\
\hline Q9UNP9 & Peptidyl-prolyl cis-trans isomerase $\mathrm{E}$ & 33.4 & 0.75 & $0.044207^{*}$ \\
\hline Q9Y2R0 & Cytochrome c oxidase assembly protein 3 homolog, mitochondrial & 11.7 & 0.792 & $0.003694^{* *}$ \\
\hline Q9Y5Y2 & Cytosolic Fe-S cluster assembly factor NUBP2 & 28.8 & 0.787 & $0.000891^{* * *}$ \\
\hline Q9Y619 & Testis-expressed sequence 264 protein & 34.2 & 0.814 & $0.047637^{*}$ \\
\hline Q9Y3Y2 & Chromatin target of PRMT1 protein & 26.4 & 0.828 & $0.008622^{* *}$ \\
\hline Q9Y4R8 & Telomere length regulation protein TEL2 homolog & 91.7 & 0.735 & $0.013443^{*}$ \\
\hline P10412 & Histone H1.4 & 21.9 & 0.655 & $0.001429^{* *}$ \\
\hline
\end{tabular}

${ }^{\text {a }} P<0.05\left(^{*}\right)$ was considered significant, and $P<0.01\left(^{* *}\right)$, as well as $<0.001\left(^{* * *}\right)$, were all considered extremely significant

were mainly divided into metabolic processes, localization, cellular process, and cellular component organization or biogenesis. The immune system process and developmental process classes were found in both RS218 and PCN033 infection groups, but not in the HB101 group. Within the cellular component class, the DEPs were mainly divided into organelle, macromolecular complex, and cell parts, and the membrane-associated ones were only identified in the meningitic strains RS218 and PCN033, not in HB101. As for molecular function, the DEPs were mainly associated with structural molecule activity, catalytic activity, and binding (Fig. 4a, Additional file 4: Table S4).

We next performed canonical pathway prediction through IPA on the DEPs. The top ranked canonical pathways in each group are shown in Fig. 4b. We found that protein kinase A signaling, eumelanin biosynthesis, EIF2 signaling, and granzyme A signaling were simultaneously enriched in both RS218 and PCN033 infection groups, but not in the HB101 group (Fig. 4b). Noticeably, granzyme A signaling was much more significantly 
Table 4 Significantly changed proteins in RS218-infected hBMECs

\begin{tabular}{|c|c|c|c|c|}
\hline Accession & Description & MW [kDa] & Fold change & $P$ value ${ }^{a}$ \\
\hline 000592 & Podocalyxin & 58.6 & 1.214 & $0.001481^{* *}$ \\
\hline 014556 & Glyceraldehyde-3-phosphate dehydrogenase, testis-specific & 44.5 & 2.514 & $0.000183^{* * *}$ \\
\hline O43598 & 2'-Deoxynucleoside 5'-phosphate N-hydrolase 1 & 19.1 & 0.8 & $0.020803^{*}$ \\
\hline O76024 & Wolframin & 100.2 & 0.732 & $0.000347^{* * *}$ \\
\hline O76095 & Protein JTB & 16.3 & 0.815 & $0.026287^{*}$ \\
\hline O95989 & Diphosphoinositol polyphosphate phosphohydrolase 1 & 19.5 & 0.821 & $0.003332^{* *}$ \\
\hline P05067 & Amyloid beta A4 protein & 86.9 & 0.813 & $0.004913^{* *}$ \\
\hline P10412 & Histone H1.4 & 21.9 & 1.271 & $0.001736^{* *}$ \\
\hline P11532 & Dystrophin & 426.5 & 0.799 & $0.014535^{*}$ \\
\hline P14174 & Macrophage migration inhibitory factor & 12.5 & 1.276 & $0.008267^{* *}$ \\
\hline P16401 & Histone H1.5 & 22.6 & 1.221 & $0.025445^{*}$ \\
\hline P16402 & Histone H1.3 & 22.3 & 1.306 & $0.001514^{* *}$ \\
\hline P16403 & Histone H1.2 & 21.4 & 1.332 & $0.021727^{*}$ \\
\hline P30154 & Serine/threonine-protein phosphatase $2 \mathrm{~A} 65 \mathrm{kDa}$ regulatory subunit $\mathrm{A}$ beta isoform & 66.2 & 0.809 & $0.005474^{* *}$ \\
\hline P35527 & Keratin, type I cytoskeletal 9 & 62 & 0.822 & $0.038701^{*}$ \\
\hline P42167 & Lamina-associated polypeptide 2, isoforms beta/gamma & 50.6 & 0.826 & $0.0494^{*}$ \\
\hline P46781 & $40 \mathrm{~S}$ ribosomal protein 59 & 22.6 & 1.207 & $0.013518^{*}$ \\
\hline P50402 & Emerin & 29 & 0.8 & $0.000916^{* * *}$ \\
\hline P52756 & RNA-binding protein 5 & 92.1 & 0.74 & $4.23 \mathrm{E}-06^{* * *}$ \\
\hline P55789 & FAD-linked sulfhydryl oxidase ALR & 23.4 & 1.537 & $0.014932^{*}$ \\
\hline P61313 & $60 S$ ribosomal protein L15 & 24.1 & 1.286 & $0.000236^{* * *}$ \\
\hline P62380 & TATA box-binding protein-like protein 1 & 20.9 & 0.66 & $0.008696^{* *}$ \\
\hline Q07020 & $60 S$ ribosomal protein L18 & 21.6 & 1.367 & $0.002799^{* *}$ \\
\hline Q4V339 & COBW domain-containing protein 6 & 43.9 & 0.756 & $0.00457^{* *}$ \\
\hline Q8N4H5 & Mitochondrial import receptor subunit TOM5 homolog & 6 & 1.223 & $0.000783^{* * *}$ \\
\hline Q8ND56 & Protein LSM14 homolog A & 50.5 & 0.793 & $0.017061^{*}$ \\
\hline Q96BZ8 & Leukocyte receptor cluster member 1 & 30.5 & 0.693 & $0.005542^{* *}$ \\
\hline Q96HP4 & Oxidoreductase NAD-binding domain-containing protein 1 & 34.8 & 3.845 & $0.008111^{* *}$ \\
\hline Q96KR1 & Zinc finger RNA-binding protein & 116.9 & 0.811 & $0.01368^{*}$ \\
\hline Q96LB3 & Intraflagellar transport protein 74 homolog & 69.2 & 0.71 & $0.012006^{*}$ \\
\hline Q96P47 & Arf-GAP with GTPase, ANK repeat and PH domain-containing protein 3 & 95 & 0.783 & $0.004713^{* *}$ \\
\hline Q99538 & Legumain & 49.4 & 0.692 & $0.001173^{* *}$ \\
\hline Q9BTA9 & WW domain-containing adapter protein with coiled-coil & 70.7 & 0.743 & $0.01886^{*}$ \\
\hline Q9BZF9 & Uveal autoantigen with coiled-coil domains and ankyrin repeats & 162.4 & 0.824 & $0.031539^{*}$ \\
\hline Q9H7B2 & Ribosome production factor 2 homolog & 35.6 & 1.367 & $0.020862^{*}$ \\
\hline Q9HCD5 & Nuclear receptor coactivator 5 & 65.5 & 0.771 & $0.001324^{* *}$ \\
\hline Q9NPD3 & Exosome complex component RRP41 & 26.4 & 0.784 & $0.015931^{*}$ \\
\hline Q9NZR1 & Tropomodulin-2 & 39.6 & 1.216 & $0.030742^{*}$ \\
\hline Q9U110 & Translation initiation factor elF-2B subunit delta & 57.5 & 0.828 & $0.001214^{* *}$ \\
\hline Q9UIC8 & Leucine carboxyl methyltransferase 1 & 38.4 & 0.811 & $0.0312^{*}$ \\
\hline Q9UK41 & Vacuolar protein sorting-associated protein 28 homolog & 25.4 & 0.715 & $0.032545^{*}$ \\
\hline Q9Y4R8 & Telomere length regulation protein TEL2 homolog & 91.7 & 0.807 & $0.019858^{*}$ \\
\hline Q9Y5V3 & Melanoma-associated antigen D1 & 86.1 & 1.238 & $0.007536^{* *}$ \\
\hline
\end{tabular}

${ }^{a} P<0.05\left(^{*}\right)$ was considered significant, and $P<0.01\left({ }^{* *}\right)$, as well as $<0.001(* *)$, were all considered extremely significant 
Table 5 The distinct differential proteins in hBMECs in response to meningitic E. coli strains PCN033 and RS218

\begin{tabular}{|c|c|c|c|c|c|}
\hline \multirow[t]{2}{*}{ ID } & \multirow[t]{2}{*}{ Name } & \multirow[t]{2}{*}{ Protein } & \multicolumn{3}{|c|}{ Fold Change } \\
\hline & & & $\mathrm{RS} 218$ & PCN033 & $\mathrm{HB101}$ \\
\hline Q9NPD3 & EXOSC4 & Exosome complex component RRP41 & 0.8 & 0.759 & 0.74 \\
\hline Q96LB3 & IFT74 & Intraflagellar transport protein 74 homolog & 0.7 & 0.543 & / \\
\hline P11532 & DMD & Dystrophin & 0.8 & 0.691 & / \\
\hline P52756 & RBM5 & RNA-binding protein 5 & 0.7 & 0.758 & / \\
\hline Q4V339 & CBWD6 & COBW domain-containing protein 6 & 0.8 & 0.747 & / \\
\hline Q9Y4R8 & TELO2 & Telomere length regulation protein TEL2 homolog & 0.8 & 0.735 & / \\
\hline P35527 & KRT9 & Keratin, type I cytoskeletal 9 & 0.8 & 0.72 & / \\
\hline P62380 & TBOL1 & TATA box-binding protein-like protein 1 & 0.7 & 0.621 & / \\
\hline P16403 & HIST1H1C & Histone H1.2 & 1.3 & 0.572 & / \\
\hline P16402 & HIST1H1D & Histone H1.3 & 1.3 & 0.6 & / \\
\hline P10412 & HIST1H1E & Histone H1.4 & 1.3 & 0.655 & / \\
\hline P16401 & HIST1H1B & Histone H1.5 & 1.2 & 0.631 & / \\
\hline P14174 & MIF & Macrophage migration inhibitory factor & 1.3 & 1.486 & / \\
\hline
\end{tabular}

enriched in the DEPs from both meningitic groups, suggesting a potential role for granzyme $\mathrm{A}$ in meningitic $E$. coli invasion of the BBB. Additionally, phosphatidylcholine biosynthesis I, choline biosynthesis III, and glioma invasiveness signaling were only enriched in the PCN033 group, while neuronal NOS signaling and regulation of eIF4 and p70S6K signaling were only identified in the RS218 group, which exhibited distinct signaling pathways that might have strain specificity (Fig. 4b).

The IPA tool was used to further analyze the potential networks based on the DEPs from the E. coli infections.

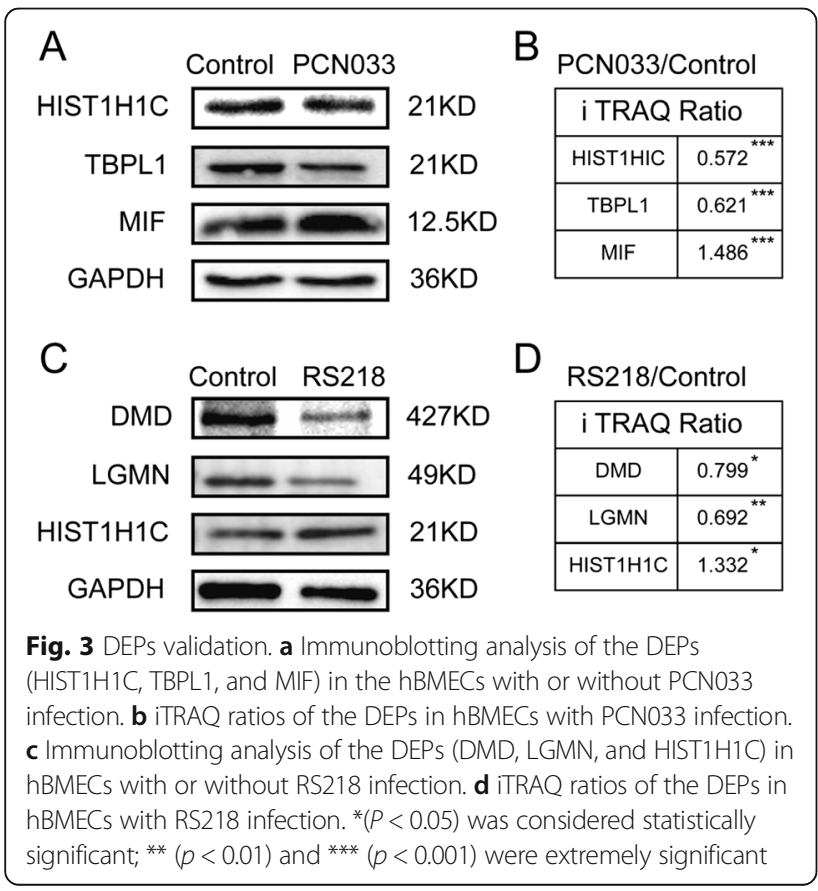

Two networks were drawn for these differential cellular proteins in response to HB101 infection (Fig. 5a, b, Additional file 5: Table S5). In addition, four networks were generated based on the DEPs from the PCN033 infection (Fig. $5 \mathrm{c}-\mathrm{f}$, Additional file 6: Table S6), while two networks were generated from the DEPs upon RS218 infection (Fig. 5g, h, Additional file 7: Table S7). It should be noted that the NF- $\mathrm{kB}$ complex, as well as ERK, were included in the networks of both PCN033 and RS218 groups, while they were not observed in the cells in response to the non-meningitic HB101 strain, suggesting that these two essential signaling molecules exert regulatory effects during meningitic $E$. coli penetration of the BBB.

\section{MIF contributes to meningitic $E$. coli-induced cytokine production and tight junction disruption}

Based on the aforementioned network analysis, we noticed the presence of MIF in the meningitic PCN033 and RS218 strain groups, suggesting potential roles for it in meningitic $E$. coli invasion of the $\mathrm{BBB}$. Here, by pretreating the hBMECs with $20 \mu \mathrm{M}$ ISO-1 (a MIF inhibitor), we found that the multiple cytokines [e.g. interleukin (IL)-6, IL-8, tumor necrosis factor (TNF)- $\alpha$, IL-1 $\beta]$ significantly induced by meningitic E. coli PCN033 or RS218 infection had decreased levels (Fig. 6a, b). Moreover, the ECIS system was applied to evaluate the potential effects of recombinant MIF protein on the barrier function of hBMECs. The results showed that recombinant MIF obviously decreased the resistance formed by the cells in a dose-dependent manner (Fig. 6c). We also observed that treatment with recombinant MIF $(200 \mathrm{ng} / \mathrm{ml})$ for 12 and $24 \mathrm{~h}$ led to decreased expression of tight junction proteins like ZO-1 and occludin (Fig. 6d); moreover, use of the 

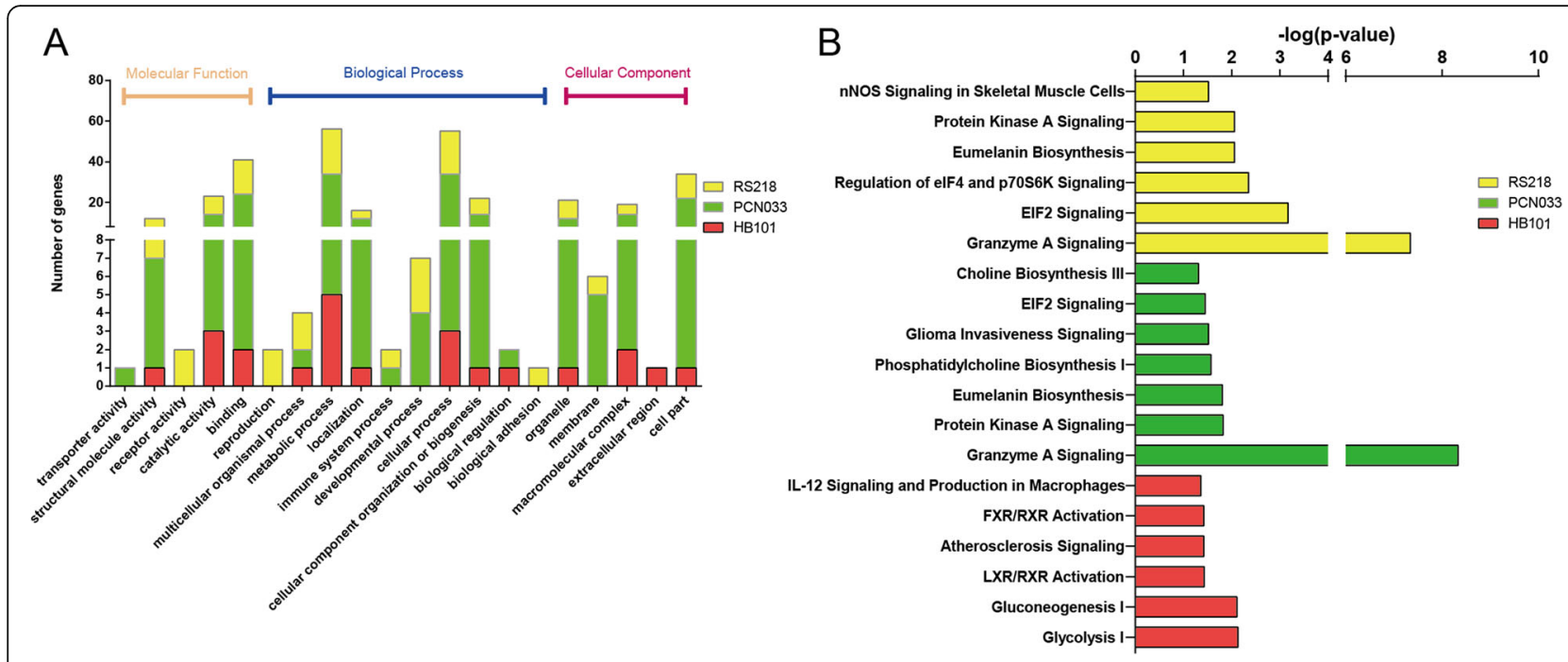

Fig. $4 \mathrm{GO}$ annotation and pathway enrichment comparison of DEPs upon meningitic or non-meningitic E. coli infection. a GO annotation characterization of the molecular functions, biological processes, and cellular components based on the DEPs. b Pathway enrichment of cellular DEPs in response to infection with HB101, PCN033, and RS218 strains

MIF inhibitor ISO-1 could partially recover the PCN033 or RS218 infection-caused downregulation of tight junction proteins like ZO-1 and Occludin (Fig. 6e, f). Together, these observations support the conclusion that MIF contributes to the induction of proinflammatory cytokines and the decrease in tight junction proteins during meningitic $E$. coli invasion of the BBB.

\section{Meningitic $E$. coli activation of NF-KB signaling mediates the production of cytokines}

As mentioned above in the network analysis, involvement of the NF- $\mathrm{kB}$ complex was observed in cells following the challenge with meningitic E. coli strains $\mathrm{PCN} 033$ and RS218, but not with non-meningitic HB101. Therefore, we investigated NF- $\mathrm{kB}$ signaling activation in hBMECs in response to infection. Phosphorylation of the NF- $\mathrm{kB}$ p 65 subunit increased significantly in response to PCN033 and RS218 infection, and this was much higher than that observed during the response to HB101 infection. Also, degradation of IkB $\alpha$ upon PCN033 or RS218 infection was much greater than that upon HB101 infection (Fig. 7a, b). Using immunofluorescence microscopy, we also observed p65 translocation to the nucleus upon PCN033 and RS218 infection (Fig. 7c), while this nuclear translocation was barely observed in response to HB101 infection (Fig. 7c). These results indicate that the NF- $\mathrm{kB}$ signaling pathway is activated during meningitic $E$. coli interaction with hBMECs. Moreover, by using the NF- $\mathrm{B} B$ inhibitor BAY11-7082, we observed that the meningitic E. coli PCN033- or RS218-induced cytokines production (including IL-6, IL-8, TNF- $\alpha$, and IL-1 $\beta$ ) was significantly decreased when compared with DMSO treatment (Fig. 7d, e). Together, these data firmly support our network analysis that the NF- $\mathrm{kB}$ signaling pathway is involved in both PCN033 and RS218 infection of hBMECs, and their activation of NF- $\mathrm{kB}$ signaling in $\mathrm{hBMECs}$ mediates the induction of proinflammatory cytokines.

MAPK signaling pathways are involved in proinflammatory cytokine induction by meningitic $E$. coli strains

Because ERK was assumed to be involved in infections with PCN033 and RS218 based on our network prediction, we next investigated the activation of MAPK pathways in hBMECs in response to meningitic E. coli. The results showed that the phosphorylation of p38, JNK, and ERK1/2 significantly increased in response to meningitic strains PCN033 or RS218 (Fig. 8a, b), indicating the activation of all three MAPK pathways in hBMECs upon meningitic $E$. coli challenge. After demonstrating the significant induction of several proinflammatory cytokines above, we next investigated whether the MAPK pathways were involved in these cytokines production. Following pretreatment with U0126 (a specific ERK1/2 inhibitor), SB202190 (a selective inhibitor of p38), and SP600125 (a JNK-specific inhibitor), the proinflammatory cytokines (IL-6, IL-8, TNF- $\alpha$, IL- $1 \beta$ ) induced in hBMECs upon PCN033 or RS218 infection were significantly reduced (to different extents), compared with that in each DMSO control group (Fig. 8c). These results indicate that the MAPK signaling pathways, including MAPK-p38, MAPK-ERK1/2, and MAPK-JNK, were all activated and at least participated in meningitic $E$. coli-induced neuroinflammatory responses.

\section{Discussion}

The iTRAQ-based proteomics, a powerful approach for obtaining comprehensive and quantitative protein 


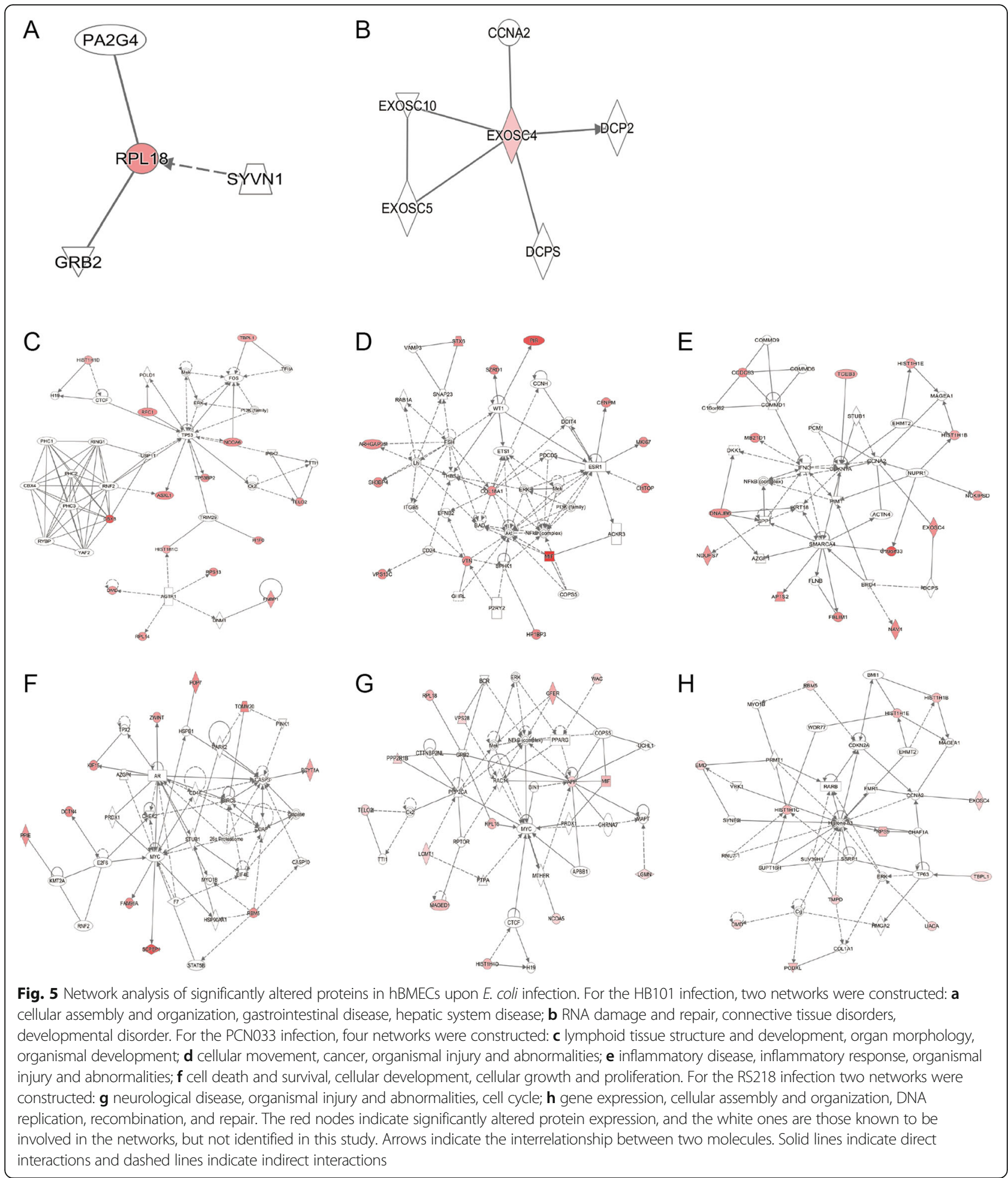

expression profiling data, has been used widely to identify and characterize potential cellular targets. In current study, we used iTRAQ to explore the proteomic differences in hBMECs in response to meningitic or non-meningitic $E$. coli infections. The E. coli strains PCN033 and RS218 were selected for this study because they are representative meningitis-causing strains capable of penetrating the $\mathrm{BBB}$ as well as inducing severe neuroinflammation [5, 20], while the E. coli strain HB101 is avirulent and non-meningitic and was therefore used as the negative control.

Based on our data, 13 significantly differentiated proteins in total were found to be shared by PCN033 and 

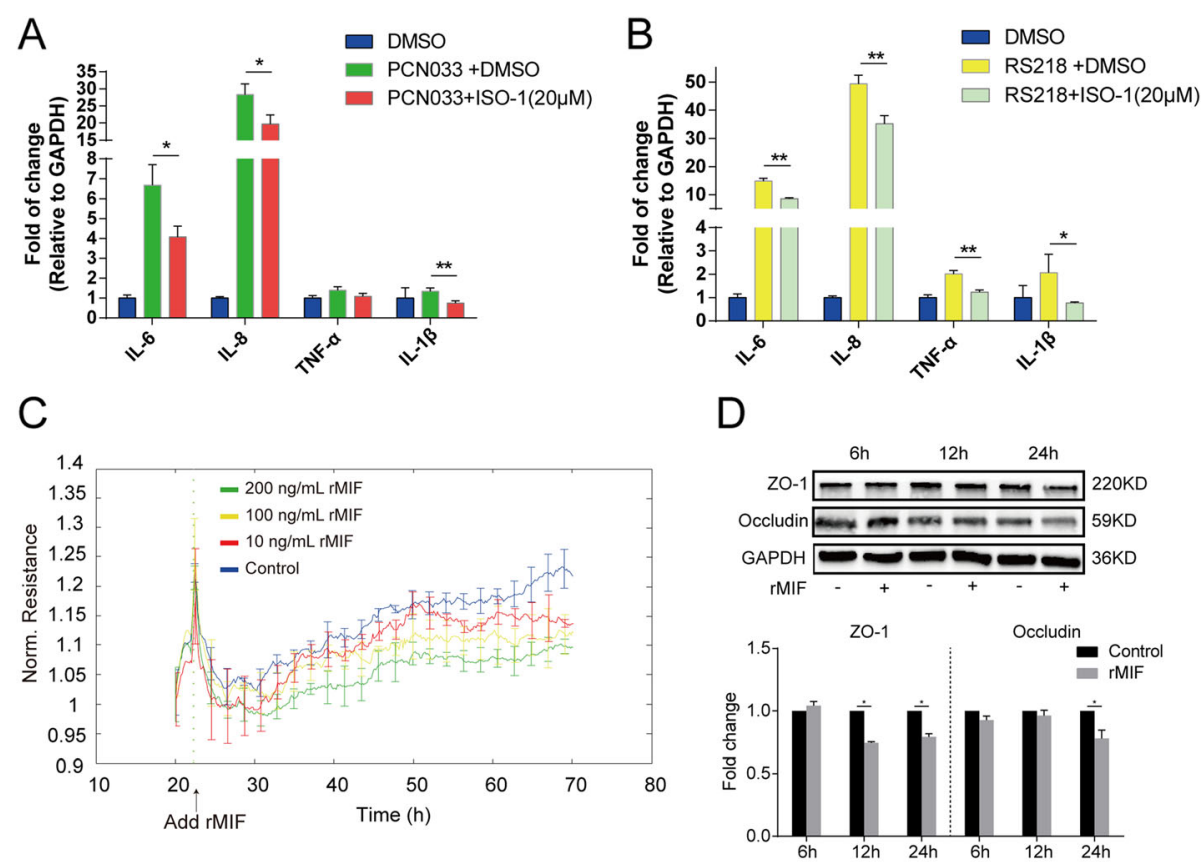

$\mathrm{E}$

$\mathrm{F}$
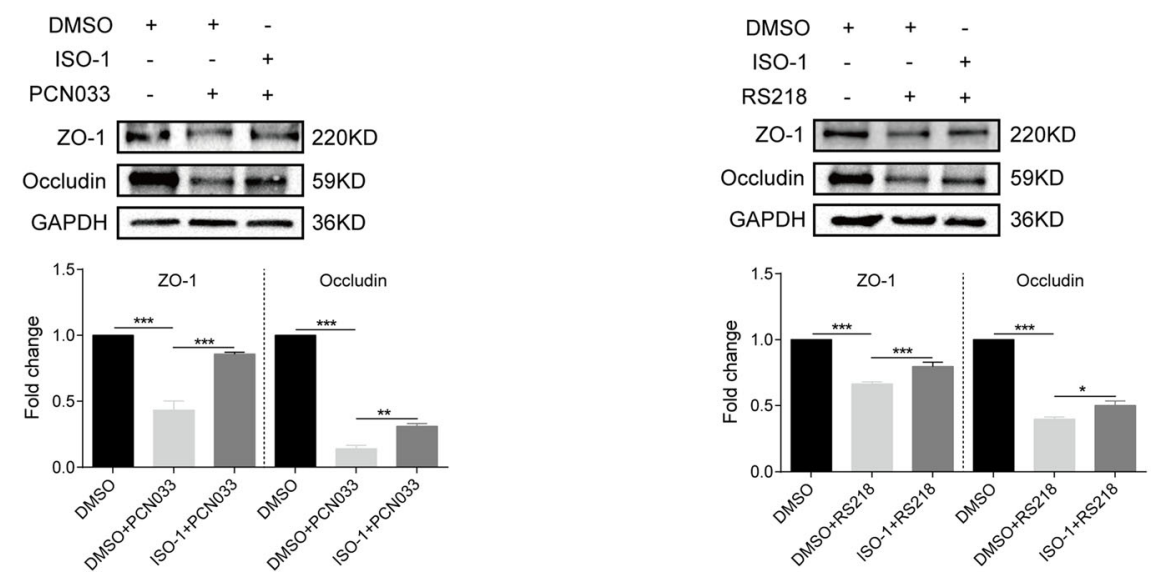

Fig. 6 MIF facilitated the bacteria-induced inflammatory response and tight junction damage in hBMECs. $\mathbf{a}$, b Real-time PCR determination of the expression of cytokines in response to the treatments. The MIF inhibitor ISO-1 (20 $\mu \mathrm{M})$ significantly attenuated the PCN033- or RS218-induced production of proinflammatory cytokines. c ECIS assay showed a dose-dependent decrease of the hBMECs resistance in response to recombinant MIF protein. $\mathbf{d}$ Recombinant MIF protein (200 ng/mL) decreased the expression of tight junction proteins ZO-1 and occludin in hBMECs along with time. The densitometry was performed to quantitatively analyze the Western bands. e, f Western blotting and densitometry analysis showed that ISO-1 treatment partially recovered PCN033- or RS218-mediated downregulation of the tight junction proteins ZO-1 and occludin. Data were expressed as the mean \pm standard deviation (mean \pm SD) from three replicates or analyses $(n=3) . P<0.05\left(^{*}\right)$ was considered statistically significant; $p<0.01(* *)$ and $p<0.001{ }^{(* * *)}$ were extremely significant

RS218 (Fig. 1). They are TELO2, IFT74, CBWD6, EXOSC4, TBOL1, RBM5, KRT9, HIST1H1C, HIST1H1D, HIST1H1B, HIST1H1E, MIF, and DMD (Table 5). Among these, EXOSC4 was the only protein that was also significantly changed in response to non-meningitic E. coli HB101 (Fig. 2, Table 5). EXOSC4, a non-catalytic component of the RNA exosome machinery, has $3^{\prime}-5^{\prime}$ exoribonuclease activity and participates in a multitude of cellular RNA processing and degradation events [29]. It was reported that EXOSC4 was a potential factor involved in the maintenance of genome stability, by eliminating the RNA processing by-products and non-coding "pervasive" transcripts thereby limiting or excluding their export to the cytoplasm, or by preventing translation of aberrant mRNAs [30-32]. In lung adenocarcinoma, EXOSC4 has been reported to be extremely highly expressed and closely associated with cancer cell proliferation and 


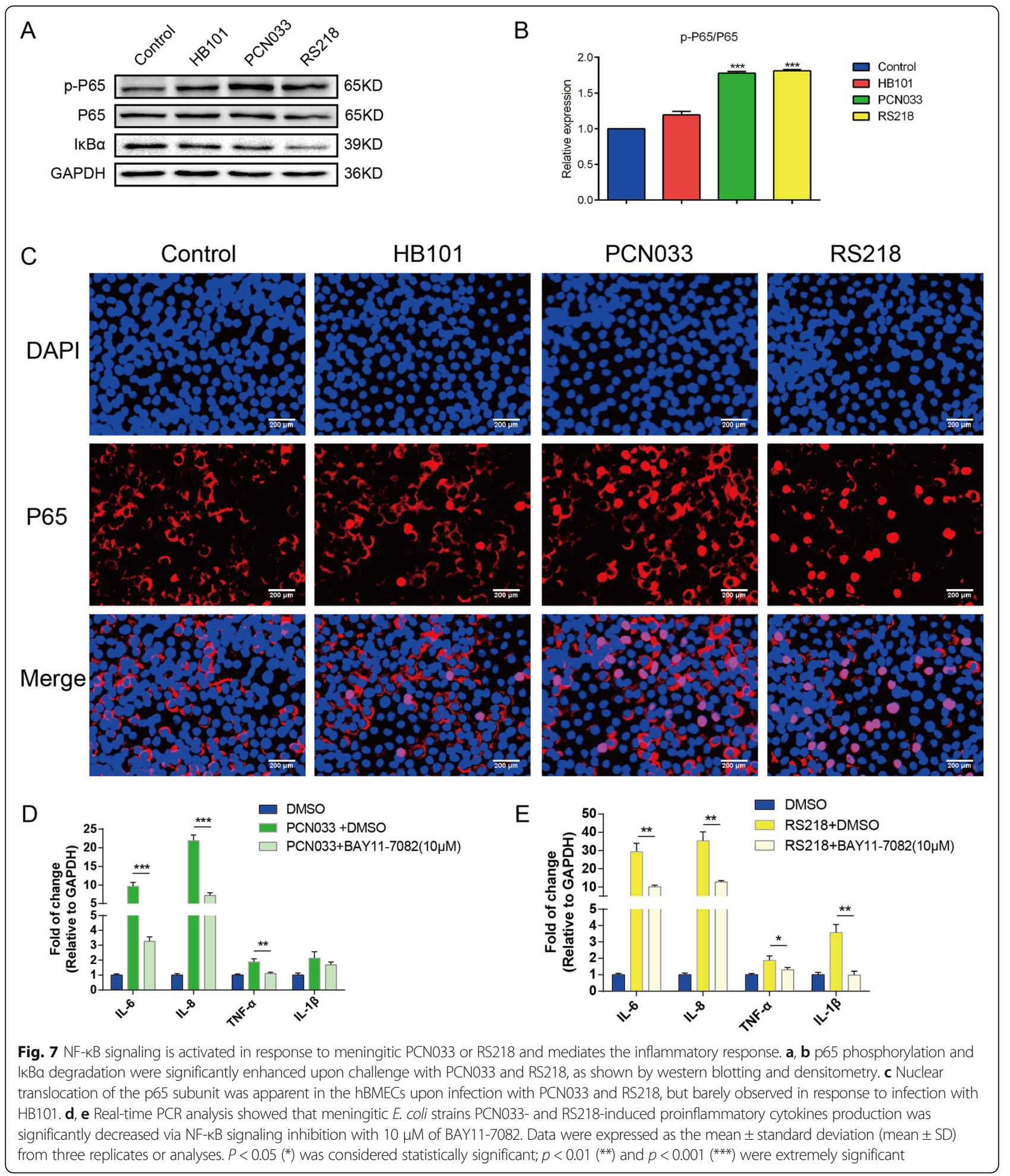

was, therefore, recognized as a new prognostic marker [30]. Similarly, in patients with liver cancer, the EXOSC4 gene was found to be highly expressed, and its knock-down commonly inhibited cancer cell growth and invasion [33]. Here, we found that EXOSC4 was commonly targeted by the meningitic and the non-meningitic $E$. coli strains, indicating that this cellular protein is a non-specific infection-related protein. Other than EXOSC4, the remaining 12 proteins were shared by the meningitic strains (PCN033 and RS218) 


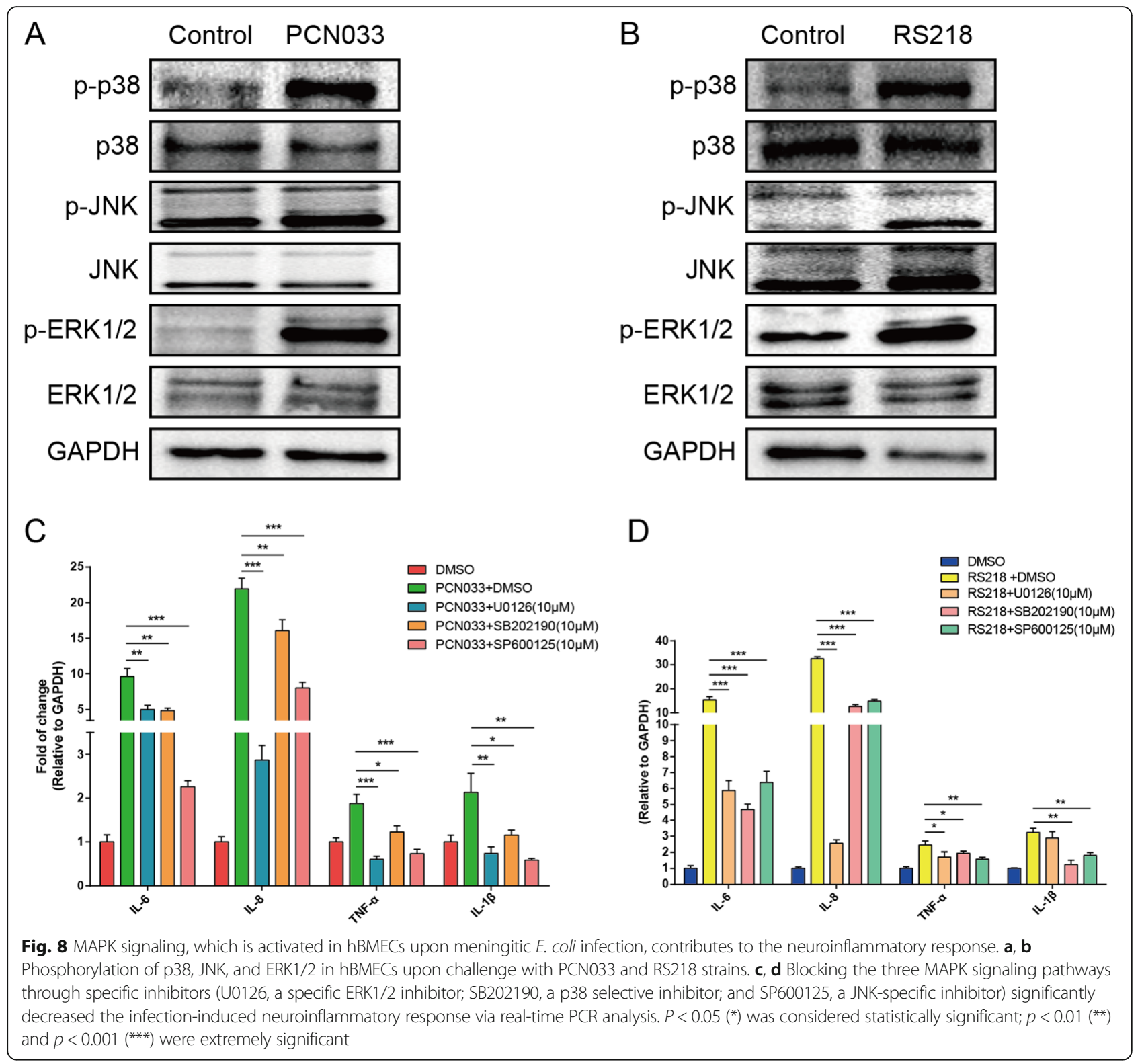

alone, suggesting that these proteins might represent the potential targets hijacked by these meningitic $E$. coli strains.

Among these 12 meningitic E. coli-specific "cellular responders," we firstly focused on MIF, which was the only one to exhibit common upregulation in response to both meningitic E. coli PCN033 and RS218 (Table 5). MIF is a proinflammatory cytokine, which has been highlighted as a key player in infection and septic shock $[34,35]$. It is reported to be involved in the cytokine storm, which facilitates the uncontrolled release of cytokines into the circulation during pathogen infection or sepsis [36]. As previously evidenced in E. coli-induced meningitis, cytokines and chemokines potentially contribute to BBB damage [5]. The burst of proinflammatory cytokines during infection may lead directly to dysfunction of the endothelial barrier and an increase in vascular permeability in the brain, thus finally leading to severe CNS injury. Moreover, MIF may be secreted by a wide variety of cells upon stimulation, and once MIF binds to its receptors (e.g., CXCR2, CXCR4, and/or CD74 [37, 38]), several downstream signal molecules such as PI3K/Akt or MAPK/ERK become activated, thus mediating the inflammatory response $[39,40]$. In the present study, the effects of MIF on meningitic E. coli-induced inflammation were also verified by the observation that the MIF inhibitor ISO-1 significantly decreased meningitic E. coli PCN033- or RS218-induced upregulation of IL-6, IL-8, IL-I $\beta$, and TNF- $\alpha$ (Fig. 5). Noticeably however, although the ISO-1 inhibitory effects were significant, there was 
still a significant induction of IL-6 and IL-8 in response to PCN033 and RS218 infection, suggesting that other "switches" for proinflammatory cytokine and chemokine generation commonly exist in response to infection. Except for its role in inflammation, we also observed the involvement of MIF in BBB damage, as evidenced by the fact that recombinant MIF was able to deconstruct the endothelial barrier by inducing a significant decrease in the junction-associated protein $\mathrm{ZO}-1$ and occludin (Fig. 6). Furthermore, when MIF inhibitor ISO-1 was used, the PCN033- and/or RS218-induced downregulation of ZO-1 and occludin was largely restored (Fig. 6). Considering the potential roles of MIF in mediating the neuroinflammatory response as well as in inducing BBB disruption, it is possible that MIF may represent a novel and potential target for clinical prevention and therapy for $E$. coli meningitis.

Our IPA-based canonical pathways prediction suggested that protein kinase A signaling, eumelanin biosynthesis, EIF2 signaling, and granzyme A signaling were simultaneously enriched in hBMECs upon infection with RS218 and PCN033, but not with HB101. Among these processes, granzyme A signaling was much more significantly enriched. In the RS218 group, HIST1H1B, HIST1H1C, HIST1H1E, and HIST1H1D are included in granzyme A signaling, while in the PCN033 group, HIST1H1B, HIST1H1C, HIST1H1E, HIST1H1D, and H1F0 are involved (Additional file 6: Table S6). Granzyme A was identified as a cytotoxic $\mathrm{T}$ lymphocyte protease with multiple roles in infectious diseases. For example, several studies have shown that granzyme A is highly expressed in patients with tuberculosis and may represent a promising diagnostic marker distinct from IFN- $\gamma$ to discriminate between patients with tuberculosis and other pulmonary diseases [41-43]. Granzyme A is also considered to participate in the host defense response in multiple ways, such as by generating superoxide and inactivating the oxidative defense enzymes that kill intracellular parasites [44], by unfavorably impairing host defenses during Streptococcus pneumoniae pneumonia [45], by performing as a proinflammatory protease that cleaves IL- $1 \beta$ intracellularly into bioactive IL-1 $\beta[46,47]$, or by causing detachment of alveolar epithelial A549 cells accompanied by promotion of IL-8 release [48]. Here, in the present study, granzyme A signaling was significantly enriched by cellular differentiated proteins in response to both meningitic $E$. coli strains, but not in non-meningitic E. coli HB101. This result probably indicates that granzyme A could be a potential indicator of $E$. coli meningitis, but further supportive evidences are needed.

Based on the IPA functional network analysis, we also noticed that the NF- $\mathrm{kB}$ complex and MAPK/ERK signaling were involved in both PCN033 and RS218 infection of hBMECs, but barely in the HB101 group. The NF- $k B$ complex comprises a family of closely related transcription factors with important roles in regulating the gene expression involved in inflammation and the immune response [49]. The NF- $\mathrm{kB}$ activation process is induced by the phosphorylation of serine residues in IkB proteins, which are subjected to ubiquitination and proteasome degradation and, subsequently, phosphorylation and nuclear translocation of the p65 subunit. Early studies have shown that NF- $\mathrm{kB}$ is activated in bacteria-induced CNS infections [50], and NF- $\mathrm{kB}$ inhibitors have been found to reduce neuroinflammation [51] as well as protect rat brains from inflammatory injury following transient focal cerebral ischemia [52] and pneumococcal meningitis [53]. In E. coli, it has been evidenced that OmpA ${ }^{+}$. coli can induce ICAM-1 expression in hBMECs by activating NF- $\mathrm{KB}$ signaling [54] and that the $\mathrm{IbeA}^{+} E$. coli $\mathrm{K} 1$ strain can also induce activation and nuclear translocation of NF-kB in hBMECs [55]. In the current study, by western blotting, we also showed that the NF- $k B$ pathway was activated more in hBMECs infected by meningitic strains PCN033 and RS218 compared with that by HB101 infection, where the phosphorylation of p65 and degradation of IкB $\alpha$ were compared, as well as with the immunofluorescence experiments that showed the nuclear translocation of p65. Not unexpectedly, treating hBMECs with the NF- $\mathrm{KB}$ inhibitor BAY11-7082 significantly attenuated those cytokines induction during meningitic $E$. coli infection, suggesting that NF- $\mathrm{kB}$ signaling works potently in mediating the neuroinflammatory response.

Likewise, we found that the effects of MAPK signaling were similarly associated with both PCN033 and RS218 infection of hBMECs. MAPK signaling cascades actually involve three major pathways: JNK (which acts as mediator of extracellular stress responses), ERK1/2 (which mediates proliferative stimuli), and p38 (which is also involved in mediating extracellular stress responses, particularly by regulating cytokine expression) [56]. Our IPA network analysis indicated the involvement of ERK during infection with meningitic E. coli $\mathrm{PCN} 033$ and RS218, which is consistent with our previous finding that MAPK/ERK signaling is involved in infection and mediates the induction of VEGFA and Snail-1 by the meningitic strain PCNO33 [5]; however, via western blotting we showed the activation of all these three signaling molecules in response to PCN033 and RS218 infection. Also, by using specific inhibitors against ERK1/2, p38, and JNK, we observed that inhibition of all three MAPK pathways significantly decreased the infection-induced upregulation of proinflammatory cytokines IL-6, IL-8, IL-I $\beta$, and TNF- $\alpha$. Therefore, collectively these data largely support the viewpoint that all three major MAPK signaling pathways play potent roles in meningitic $E$. coli infection and induce neuroinflammatory responses. 


\section{Conclusions}

In our study, using the iTRAQ proteomics approach, we compared and analyzed the DEPs in hBMECs infected with meningitic or non-meningitic E. coli strains. Twelve DEPs were identified as the commonly responding proteins in hBMECs upon infection with meningitic $E$. coli strains PCN033 and RS218, except for only one cellular protein shared by both meningitic and non-meningitic strains. Our data revealed MIF to be an important contributor to meningitic E. coli-induced cytokine production and tight junction disruption, while also showing that the NF-kB and MAPK signaling pathways are involved in the infection process. Comparing and profiling these differential cellular proteins in hBMECs in response to meningitic $E$. coli strains should open up further research on host responses against meningitic strains and help with the development of more targets for better prevention and therapeutic control of $E$. coli meningitis.

\section{Additional files}

Additional file 1: Table S1. Protein profile of HB101-infected hBMECs. (XLSX $287 \mathrm{~kb}$ )

Additional file 2: Table S2. Protein profile of PCN033-infected hBMECs. (XLSX 290 kb)

Additional file 3: Table S3. Protein profile of RS218-infected hBMECs. (XLSX $289 \mathrm{~kb}$ )

Additional file 4: Table S4. GO term annotation of DEPs. (DOCX 15 kb)

Additional file 5: Table S5. Ingenuity Canonical Pathways of HB101-

infected group. (XLSX $71 \mathrm{~kb}$ )

Additional file 6: Table S6. Ingenuity Canonical Pathways of PCN033infected group. (XLSX $70 \mathrm{~kb}$ )

Additional file 7: Table S7. Ingenuity Canonical Pathways of RS218infected group. (XLSX $71 \mathrm{~kb}$ )

Additional file 8: Table S8. The potential networks in HB101-infected group. (XLSX $70 \mathrm{~kb}$ )

Additional file 9: Table S9. The potential networks in PCN033-infected group. (XLSX $72 \mathrm{~kb}$ )

Additional file 10: Table S10. The potential networks in RS218-infected group. (XLSX $71 \mathrm{~kb}$ )

\section{Abbreviations}

BBB: Blood-brain barrier; BMECs: Brain microvascular endothelial cells; CNS: Central nervous system; CSF: Cerebrospinal fluid; DEPs: Differentially expressed proteins; DMD: Dystrophin; E. coli: Escherichia coli; ECIS: Electric cell-substrate impedance sensing; EGFR: Epidermal growth factor receptor; ERK1/2: Extracellular signal-regulated kinases 1 and 2; ExPEC: Extraintestinal pathogenic Escherichia coli; GO: Gene Ontology; ICAM-1: Intercellular adhesion molecule-1; IL-1 $\beta$ : Interleukin 1 beta; IL-8: Interleukin-8; IPA: Ingenuity Pathways Analysis; ISO-1: (S, R)-3-(4-Hydroxyphenyl)-4, 5dihydro-5-isoxazole acetic acid methyl ester DAPI4'-6-Diamidino-2phenylindole; iTRAQ: Isobaric tags for relative and absolute quantification; JNK: c-Jun N-terminal kinase; KEGG: Kyoto encyclopedia of genes and genomes; LC-MS/MS: Liquid chromatography tandem mass spectrometry; LGMN: Legumain; MAPK: Mitogen-activated protein kinase; MIF: Macrophage migration inhibitory factor; NF-kB: Nuclear factor-kB; NOS: Nitric oxide synthase; PI3K: Phosphatidylinositol 3-kinase; S1P: Sphingosine-1-phosphate; SCX: Strong cation exchange chromatography; TBPL1: TATA box-binding protein-like protein 1; TEAB: Tetraethyl-ammonium bromide; TEER: Trans- endothelial electric resistance; TNF-a: Tumor necrosis factor-alpha; VEGFA: Vascular endothelial growth factor A; ZO-1: Zonula occludens-1, IL-6, interleukin-6

\section{Acknowledgements}

We would like to thank Prof. Kwang Sik Kim in Johns Hopkins University School of Medicine to kindly provide the hBMECs cells.

\section{Funding}

This work was supported by grants from the National Key R\&D Program of China (2016YFD0500406), the National Natural Science Foundation of China (NSFC) (Nos. 31772736, 31502062), the Outstanding youth project of Natural Science Foundation in Hubei Province (2018CFA070), and the Fundamental Research Funds for the Central Universities (Program No. 2662018PY032).

Availability of data and materials

There is no data, software, databases, and application/tool available apart from the reported in the present study. All data is provided in manuscript.

\section{Authors' contributions}

WTL performed all experiments and analyzed the data. YJL drafted the manuscript. RCY, JYF, LL, HW, and QC participated in project planning, and all western blot experiments. XRW conceived of the project, coordinated and supervised the experiments, and revised the manuscript. XRW, CT, and HCC provide technical and administrative support. All authors read and approved the final manuscript.

Ethics approval and consent to participate

Not applicable.

\section{Consent for publication}

Not applicable.

\section{Competing interests}

The authors declare that they have no competing interests.

\section{Publisher's Note}

Springer Nature remains neutral with regard to jurisdictional claims in published maps and institutional affiliations.

\section{Author details}

${ }^{1}$ The Cooperative Innovation Center for Sustainable Pig Production, Huazhong Agricultural University, Wuhan 430070, Hubei, China. ${ }^{2}$ College of Veterinary Medicine, Henan University of Animal Husbandry and Economy, Zhengzhou 450046, Henan, China. ${ }^{3}$ State Key Laboratory of Agricultural Microbiology, College of Veterinary Medicine, Huazhong Agricultural University, Wuhan 430070, Hubei, China.

Received: 11 July 2018 Accepted: 2 October 2018

Published online: 19 October 2018

References

1. Kim KS. Pathogenesis of bacterial meningitis: from bacteraemia to neuronal injury. Nat Rev Neurosci. 2003;4:376-85.

2. Kim KS. Mechanisms of microbial traversal of the blood-brain barrier. Nat Rev Microbiol. 2008;6:625-34

3. Kim KS. Acute bacterial meningitis in infants and children. Lancet Infect Dis. 2010;10:32-42.

4. Candelario-Jalil E, Yang Y, Rosenberg GA. Diverse roles of matrix metalloproteinases and tissue inhibitors of metalloproteinases in neuroinflammation and cerebral ischemia. Neuroscience. 2009;158:983-94.

5. Yang RC, Liu WT, Miao L, Yang XP, Fu JY, Dou BB, Cai AL, Zong X, Tan C, Chen HC, Wang XR. Induction of VEGFA and Snail-1 by meningitic Escherichia coli mediates disruption of the blood-brain barrier. Oncotarget. 2016;7:63839-55.

6. Stins MF, Badger J, Sik Kim K. Bacterial invasion and transcytosis in transfected human brain microvascular endothelial cells. Microb Pathog. 2001;30:19-28.

7. Stins MF, Gilles F, Kim KS. Selective expression of adhesion molecules on human brain microvascular endothelial cells. J Neuroimmunol. 1997; 76:81-90 
8. Das A, Asatryan L, Reddy MA, Wass CA, Stins MF, Joshi S, Bonventre JV, Kim KS. Differential role of cytosolic phospholipase A2 in the invasion of brain microvascular endothelial cells by Escherichia coli and Listeria monocytogenes. J Infect Dis. 2001;184:732-7.

9. Kim KS, Itabashi H, Gemski P, Sadoff J, Warren RL, Cross AS. The K1 capsule is the critical determinant in the development of Escherichia coli meningitis in the rat. J Clin Invest. 1992;90:897-905.

10. Burkhart A, Thomsen LB, Thomsen MS, Lichota J, Fazakas C, Krizbai I, Moos T. Transfection of brain capillary endothelial cells in primary culture with defined blood-brain barrier properties. Fluids Barriers CNS 2015;12:19.

11. Eigenmann DE, Xue G, Kim KS, Moses AV, Hamburger M, Oufir M. Comparative study of four immortalized human brain capillary endothelial cell lines, hCMEC/D3, hBMEC, TY10, and BB19, and optimization of culture conditions, for an in vitro blood-brain barrier model for drug permeability studies. Fluids Barriers CNS. 2013;10:33.

12. Abbott NJ. Blood-brain barrier structure and function and the challenges for CNS drug delivery. J Inherit Metab Dis. 2013;36:437-49.

13. Tajes M, Ramos-Fernandez E, Weng-Jiang X, Bosch-Morato M, Guivernau B, Eraso-Pichot A, Salvador B, Fernandez-Busquets X, Roquer J, Munoz FJ. The blood-brain barrier: structure, function and therapeutic approaches to cross it. Mol Membr Biol. 2014;31:152-67.

14. Hoffman JA, Badger JL, Zhang Y, Huang SH, Kim KS. Escherichia coli K1 asIA contributes to invasion of brain microvascular endothelial cells in vitro and in vivo. Infect Immun. 2000;68:5062-7.

15. Wang Y, Kim KS. Role of OmpA and IbeB in Escherichia coli K1 invasion of brain microvascular endothelial cells in vitro and in vivo. Pediatr Res. 2002; 51:559-63.

16. Reddy MA, Prasadarao NV, Wass CA, Kim KS. Phosphatidylinositol 3-kinase activation and interaction with focal adhesion kinase in Escherichia coli K1 invasion of human brain microvascular endothelial cells. J Biol Chem. 2000; 275:36769-74.

17. Khan NA, Wang Y, Kim KJ, Chung JW, Wass CA, Kim KS. Cytotoxic necrotizing factor-1 contributes to Escherichia coli K1 invasion of the central nervous system. J Biol Chem. 2002;277:15607-12.

18. Reddy MA, Wass CA, Kim KS, Schlaepfer DD, Prasadarao NV. Involvement of focal adhesion kinase in Escherichia coli invasion of human brain microvascular endothelial cells. Infect Immun. 2000;68:6423-30.

19. Chung JW, Hong SJ, Kim KJ, Goti D, Stins MF, Shin S, Dawson VL, Dawson TM, Kim KS. 37-kDa laminin receptor precursor modulates cytotoxic necrotizing factor 1-mediated RhoA activation and bacterial uptake. J Biol Chem. 2003;278:16857-62.

20. Wang X, Maruvada R, Morris AJ, Liu JO, Wolfgang MJ, Baek DJ, Bittman R, Kim KS. Sphingosine 1-phosphate activation of EGFR as a novel target for meningitic Escherichia coli penetration of the blood-brain barrier. PLoS Pathog. 2016;12:e1005926.

21. Wijetunge DS, Katani R, Kapur V, Kariyawasam S. Complete genome sequence of Escherichia coli strain RS218 (O18:H7:K1), associated with neonatal meningitis. Genome Announc. 2015:3:e00804-15.

22. Tan C, Xu Z, Zheng H, Liu W, Tang X, Shou J, Wu B, Wang S, Zhao GP, Chen $\mathrm{H}$. Genome sequence of a porcine extraintestinal pathogenic Escherichia coli strain. J Bacteriol. 2011;193:5038.

23. Liu C, Zheng H, Yang M, Xu Z, Wang X, Wei L, Tang B, Liu F, Zhang Y, Ding $Y$, et al. Genome analysis and in vivo virulence of porcine extraintestinal pathogenic Escherichia coli strain PCN033. BMC Genomics. 2015;16:717.

24. Tan C, Tang X, Zhang X, Ding Y, Zhao Z, Wu B, Cai X, Liu Z, He Q, Chen H. Serotypes and virulence genes of extraintestinal pathogenic Escherichia coli isolates from diseased pigs in China. Vet J. 2012;192:483-8.

25. Zhu L, Maruvada R, Sapirstein A, Malik KU, Peters-Golden M, Kim KS. Arachidonic acid metabolism regulates Escherichia coli penetration of the blood-brain barrier. Infect Immun. 2010;78:4302-10.

26. Khan NA, Kim Y, Shin S, Kim KS. FimH-mediated Escherichia coli K1 invasion of human brain microvascular endothelial cells. Cell Microbiol. 2007:9:169-78.

27. Yang R, Huang F, Fu J, Dou B, Xu B, Miao L, Liu W, Yang X, Tan C, Chen H, Wang $X$. Differential transcription profiles of long non-coding RNAs in primary human brain microvascular endothelial cells in response to meningitic Escherichia coli. Sci Rep. 2016;6:38903.

28. Szulcek R, Bogaard HJ, Amerongen GPV. Electric cell-substrate impedance sensing for the quantification of endothelial proliferation, barrier function, and motility. J Vis Exp. 2014;85. https://doi.org/10.3791/51300.
29. Allmang C, Petfalski E, Podtelejnikov A, Mann M, Tollervey D, Mitchell P. The yeast exosome and human $\mathrm{PM}-\mathrm{SCl}$ are related complexes of $3^{\prime}-->5^{\prime}$ exonucleases. Genes Dev. 1999;13:2148-58.

30. O'Byrne K, Paquet N, Box JK, Adams M, Richard D. 17P examination of EXOSC 4 as a new prognostic marker and a novel therapeutic avenue in lung adenocarcinoma. J Thorac Oncol. 2016;11:S63.

31. Basu U, Meng FL, Keim C, Grinstein V, Pefanis E, Eccleston J, Zhang T, Myers D, Wasserman CR, Wesemann DR, et al. The RNA exosome targets the AID cytidine deaminase to both strands of transcribed duplex DNA substrates. Cell. 2011;144:353-63.

32. Van Dijk EL, Schilders G, Pruijn GJ. Human cell growth requires a functional cytoplasmic exosome, which is involved in various mRNA decay pathways. RNA. 2007:13:1027-35.

33. Stefanska B, Cheishvili D, Suderman M, Arakelian A, Huang J, Hallett M, Han ZG, Al-Mahtab M, Akbar SM, Khan WA, et al. Genome-wide study of hypomethylated and induced genes in patients with liver cancer unravels novel anticancer targets. Clin Cancer Res. 2014;20:3118-32.

34. Rosado Jde D, Rodriguez-Sosa M. Macrophage migration inhibitory factor (MIF): a key player in protozoan infections. Int J Biol Sci. 2011;7:1239-56.

35. Delaloye J, De Bruin IJ, Darling KE, Reymond MK, Sweep FC, Roger T, Calandra T, Cavassini M. Increased macrophage migration inhibitory factor (MIF) plasma levels in acute HIV-1 infection. Cytokine. 2012;60:338-40.

36. Pang T, Cardosa MJ, Guzman MG. Of cascades and perfect storms: the immunopathogenesis of dengue haemorrhagic fever-dengue shock syndrome (DHF/DSS). Immunol Cell Biol. 2007;85:43-5.

37. Bernhagen J, Krohn R, Lue H, Gregory JL, Zernecke A, Koenen RR, Dewor M, Georgiev I, Schober A, Leng L, et al. MIF is a noncognate ligand of CXC chemokine receptors in inflammatory and atherogenic cell recruitment. Nat Med. 2007;13:587-96.

38. Schwartz V, Lue H, Kraemer S, Korbiel J, Krohn R, Ohl K, Bucala R, Weber C, Bernhagen J. A functional heteromeric MIF receptor formed by CD74 and CXCR4. FEBS Lett. 2009:583:2749-57.

39. Lue H, Kapurniotu A, Fingerle-Rowson G, Roger T, Leng L, Thiele M, Calandra T, Bucala R, Bernhagen J. Rapid and transient activation of the ERK MAPK signalling pathway by macrophage migration inhibitory factor (MIF) and dependence on JAB1/CSN5 and Src kinase activity. Cell Signal. 2006;18:688-703.

40. Lue H, Thiele M, Franz J, Dahl E, Speckgens S, Leng L, Fingerle-Rowson G, Bucala R, Luscher B, Bernhagen J. Macrophage migration inhibitory factor (MIF) promotes cell survival by activation of the Akt pathway and role for CSN5/JAB1 in the control of autocrine MIF activity. Oncogene. 2007;26:5046-59.

41. Garcia-Laorden MI, Blok DC, Kager LM, Hoogendijk AJ, van Mierlo GJ, Lede IO, Rahman W, Afroz R, Ghose A, Visser CE, et al. Increased intra- and extracellular granzyme expression in patients with tuberculosis. Tuberculosis (Edinb). 2015:95:575-80.

42. Guggino G, Orlando V, Cutrera S, La Manna MP, Di Liberto D, Vanini V, Petruccioli E, Dieli F, Goletti D, Caccamo N. Granzyme A as a potential biomarker of Mycobacterium tuberculosis infection and disease. Immunol Lett. 2015;166:87-91.

43. Laux da Costa L, Delcroix M, Dalla Costa ER, Prestes IV, Milano M, Francis SS, Unis G, Silva DR, Riley LW, Rossetti ML. A real-time PCR signature to discriminate between tuberculosis and other pulmonary diseases. Tuberculosis (Edinb). 2015:95:421-5.

44. Dotiwala F, Mulik S, Polidoro RB, Ansara JA, Burleigh BA, Walch M, Gazzinelli RT, Lieberman J. Killer lymphocytes use granulysin, perforin and granzymes to kill intracellular parasites. Nat Med. 2016;22:210-6.

45. Van den Boogaard FE, van Gisbergen KP, Vernooy JH, Medema JP, Roelofs JJ, van Zoelen MA, Endeman H, Biesma DH, Boon L, Van't Veer C, et al. Granzyme A impairs host defense during Streptococcus pneumoniae pneumonia. Am J Physiol Lung Cell Mol Physiol. 2016;311:L507-16.

46. Pardo J, Simon MM, Froelich CJ. Granzyme A is a proinflammatory protease. Blood. 2009;114:3968 author reply 3969-3970.

47. Hildebrand D, Bode KA, Riess D, Cerny D, Waldhuber A, Rommler F, Strack J, Korten S, Orth JH, Miethke T, et al. Granzyme A produces bioactive IL-1 beta through a nonapoptotic inflammasome-independent pathway. Cell Rep. 2014;9:910-7.

48. Yoshikawa Y, Hirayasu H, Tsuzuki S, Fushiki T. Granzyme A causes detachment of alveolar epithelial A549 cells accompanied by promotion of interleukin-8 release. Biosci Biotechnol Biochem. 2008;72:2481-4.

49. Rothwarf DM, Karin M. The NF-kappa B activation pathway: a paradigm in information transfer from membrane to nucleus. Sci STKE. 1999;1999:RE1. 
50. Ichiyama T, Isumi H, Yoshitomi T, Nishikawa M, Matsubara T, Furukawa S NF-kappaB activation in cerebrospinal fluid cells from patients with meningitis. Neurol Res. 2002;24:709-12.

51. Yang XP, Fu JY, Yang RC, Liu WT, Zhang T, Yang B, Miao L, Dou BB, Tan C, Chen HC, Wang XR. EGFR transactivation contributes to neuroinflammation in Streptococcus suis meningitis. J Neuroinflammation. 2016;13:274.

52. Khan M, Elango C, Ansari MA, Singh I, Singh AK. Caffeic acid phenethyl ester reduces neurovascular inflammation and protects rat brain following transient focal cerebral ischemia. J Neurochem. 2007;102:365-77.

53. Koedel U, Bayerlein I, Paul R, Sporer B, Pfister HW. Pharmacologic interference with NF-kappaB activation attenuates central nervous system complications in experimental Pneumococcal meningitis. J Infect Dis. 2000;182:1437-45.

54. Selvaraj SK, Periandythevar P, Prasadarao NV. Outer membrane protein A of Escherichia coli K1 selectively enhances the expression of intercellular adhesion molecule-1 in brain microvascular endothelial cells. Microbes Infect. 2007:9:547-57.

55. Chi F, Bo T, Wu CH, Jong A, Huang SH. Vimentin and PSF act in concert to regulate $\mathrm{lbeA}+\mathrm{E}$. coli $\mathrm{K} 1$ induced activation and nuclear translocation of NF-kappaB in human brain endothelial cells. PLoS One. 2012;7:e35862.

56. Ramsauer K, Sadzak I, Porras A, Pilz A, Nebreda AR, Decker T, Kovarik P. p38 MAPK enhances STAT1-dependent transcription independently of Ser-727 phosphorylation. Proc Natl Acad Sci U S A. 2002;99:12859-64.

Ready to submit your research? Choose BMC and benefit from:

- fast, convenient online submission

- thorough peer review by experienced researchers in your field

- rapid publication on acceptance

- support for research data, including large and complex data types

- gold Open Access which fosters wider collaboration and increased citations

- maximum visibility for your research: over $100 \mathrm{M}$ website views per year

At $\mathrm{BMC}$, research is always in progress.

Learn more biomedcentral.com/submissions 